\title{
Uranium isotopes and dissolved organic carbon in loess permafrost: Modeling the age of ancient ice
}

\author{
Authors: S.A. Ewing, J.B. Paces, J.A. O'Donnell, M.T. \\ Jorgenson, M.Z. Kanevskiy, G.R. Aiken, Y. Shur, \\ J.W. Harden, \& R. Striegl
}

NOTICE: this is the author's version of a work that was accepted for publication in Geochimica et Cosmochimica Acta. Changes resulting from the publishing process, such as peer review, editing, corrections, structural formatting, and other quality control mechanisms may not be reflected in this document. Changes may have been made to this work since it was submitted for publication. A definitive version was subsequently published in Geochimica et Cosmochimica Acta, Volume 152, March 2015, DOI\# 10.1016/j.gca.2014.11.008

Ewing, S.A., J.B. Paces, J.A. O’Donnell, M.T. Jorgenson, M.Z. Kanevskiy, G.R. Aiken, Y. Shur, J.W. Harden, and R. Striegl. "Uranium Isotopes and Dissolved Organic Carbon in Loess Permafrost: Modeling the Age of Ancient Ice." Geochimica et Cosmochimica Acta 152 (March 2015): 143-165. doi:10.1016/j.gca.2014.11.008.

Made available through Montana State University's ScholarWorks scholarworks.montana.edu 


\title{
Uranium isotopes and dissolved organic carbon in loess permafrost: Modeling the age of ancient ice
}

\author{
S.A. Ewing ${ }^{a, b, *}$, J.B. Paces ${ }^{c}$, J.A. O’Donnell ${ }^{a, d, e, 1}$, M.T. Jorgenson ${ }^{f}$, M.Z. Kanevskiy \\ d, G.R. Aiken a, Y. Shur d, J.W. Harden 9, R. Striegl a \\ aU.S. Geological Survey, 3215 Marine St., Suite E-127, Boulder, CO 80303, U.S. \\ bMontana State University, Dept. of Land Resources and Environmental Sciences, Bozeman, MT 59717, U.S. \\ cU.S. Geological Survey, Box 25046, MS963, Denver Federal Center, Denver, CO 80225-0046, U.S. \\ dUniversity of Alaska, Fairbanks, AK, United States \\ eNational Park Service, Arctic Network, 240 W. 5th Ave., Anchorage, AK 99501, United States \\ fAlaska Ecoscience, 2332 Cordes Way, Fairbanks, AK 99709, United States \\ gU.S. Geological Survey, 345 Middlefield Rd., MS962, Menlo Park, CA 94025, United States
}

\section{Abstract}

The residence time of ice in permafrost is an indicator of past climate history, and of the resilience and vulnerability of high-latitude ecosystems to global change. Development of geochemical indicators of ground-ice residence times in perma-frost will advance understanding of the circumstances and evidence of permafrost formation, preservation, and thaw in response to climate warming and other disturbance. We used uranium isotopes to evaluate the residence time of segregated ground ice from ice-rich loess permafrost cores in central Alaska. Activity ratios of ${ }^{234} \mathrm{U}$ vs. ${ }^{238} \mathrm{U}\left({ }^{234} \mathrm{U} /{ }^{238} \mathrm{U}\right)$ in water from thawed core sections ranged between 1.163 and 1.904 due to contact of ice and associated liquid water with mineral surfaces over time. Measured $\left({ }^{234} \mathrm{U} /{ }^{238} \mathrm{U}\right)$ values in ground ice showed an overall increase with depth in a series of five neighboring cores up to $21 \mathrm{~m}$ deep. This is consistent with increasing residence time of ice with depth as a result of accumulation of loess over time, as well as characteristic ice morphologies, high segregated ice content, and wedge ice, all of which support an inter-pretation of syngenetic permafrost formation associated with loess deposition. At the same time, stratigraphic evidence indi-cates some past sediment redistribution and possibly shallow thaw among cores, with local mixing of aged thaw waters. Using measures of surface area and a leaching experiment to determine $U$ distribution, a geometric model of $\left({ }^{234} \mathrm{U} /{ }^{238} \mathrm{U}\right)$ evolution suggests mean ages of up to $\sim 200 \mathrm{ky}$ BP in the deepest core, with estimated uncertainties of up to an order of magnitude. Evidence of secondary coatings on loess grains with elevated $\left({ }^{234} \mathrm{U} /{ }^{238} \mathrm{U}\right)$ values and $U$ concentrations suggests that refine-ment of the geometric model to account for weathering processes is needed to reduce uncertainty. We suggest that in this area of deep ice-rich loess permafrost, ice bodies have been preserved from the last glacial period (10-100 ky BP), despite subse-quent fluctuations in climate, fire disturbance and vegetation. Radiocarbon $\left({ }^{14} \mathrm{C}\right)$ analysis of dissolved organic carbon (DOC) in thaw waters supports ages greater than $\sim 40$ ky BP below $10 \mathrm{~m}$. DOC concentrations in thaw waters increased with depth to maxima of $>1000$ ppm, despite little change in ice content or cryostructures. These relations suggest time-dependent production of old DOC that will be released upon permafrost thaw at a rate that is mediated by sediment transport, among other factors. 


\section{INTRODUCTION}

Over half the belowground terrestrial organic carbon (C) pool resides in permafrost that is warming and thawing at high latitudes in response to recent warming (Hugelius et al., 2014; Lachenbruch and Marshall, 1986; Osterkamp et al., 2009; Romanovsky et al., 2010; Tarnocai et al., 2009). The release and decomposition of the large amounts of organic carbon stored in permafrost soils may constitute a substantial positive feedback to the climate system (Zimov et al., 2006, 2009; Ping et al., 2008; Schuur et al., 2008; Koven et al., 2011), subject to the complex interaction between permafrost extent and factors such as plant community changes and decreasing sea ice extent (Euskirchen et al., 2006; Lawrence et al., 2008). It has been argued that much of the carbon in permafrost soils was sequestered during the Late Pleistocene, followed by extensive thaw of permafrost and release of carbon during the PleistoceneHolocene transition (Zimov et al., 2006, 2009). Understanding the relationship between known temperature fluctuation and the vulnerability or resilience of permafrost over multiple glacial cycles is critical for understanding the global carbon balance and predicting its fate in the future (Jorgenson et al., 2010; Grosse et al., 2011). Development of multiple chronometers is therefore essential for understanding the development and evolution of permafrost systems that may have existed over tens of thousands to millions of years.

Development of tools for dating permafrost has been limited by two factors. The first is the temporal constraints of commonly used chronological tools: ${ }^{14} \mathrm{C}$ has a half life of $5730 \mathrm{y}$ and can be used to date materials up to about 50 ky BP (Reimer et al., 2009). Tritium can be used to directly date ice, but its 12.32 y half life restricts its use to residence times from one year to a few hundred years (Morgenstern et al., 2010). Both ${ }^{14} \mathrm{C}$ and tritium are complicated - though not intractably - by residually elevated concentrations due to atmospheric testing of nuclear weapons in the mid-twentieth century. The second limiting factor is the potential for ice bodies to be younger than the surrounding sediment, due to thaw and drainage followed by re-accumulation and freezing of meteoric water. This possibility necessitates secondary geochronological evidence in support of dates obtained through ${ }^{14} \mathrm{C}$ analysis of solids, luminescence analysis of loess, and tephrachronology (Schirrmeister et al., 2002; Froese et al., 2008a; Jensen et al., 2008; Blinov et al., 2009). Given evidence for preservation of Pleistocene ice over timescales of $10^{5} \mathrm{y}$ (Froese et al., 2008; Reyes et al., 2010a; Vaks et al., 2013), a direct measure of the age of ice in permafrost at timescales of $10^{4}-10^{6} \mathrm{y}$ is needed.
Permafrost formed in conjunction with loess deposition occurs throughout the Arctic and Subarctic, and represents a specific mode of "syngenetic" permafrost formation, also termed yedoma (French and Shur, 2010; Kanevskiy et al., 2011). Gradual addition of eolian and organic material to frozen land surfaces - particularly in the context of productive Pleistocene steppe-tundra ecosystems - results in syngenetic loess permafrost that stores large quantities of carbon (Zimov et al., 2006), slows subsequent thaw due to high ice content (Romanovsky et al., 2010; O'Donnell et al., 2011a), preserves distinct ice morphologies (French and Shur, 2010), and by definition must increase in age with depth. Moreover, the restricted particle-size distribution in eolianderived loess and the likelihood of equiaxial grains minimizes the effect of variable soil materials over time (Fleischer, 1983; Muhs et al., 2008). Hence this type of permafrost offers a useful medium for testing indicators of permafrost chronology based on rock-water contact, and associated carbon dynamics.

In this study, we evaluate radioactive disequilibrium among uranium isotopes in thaw water (specifically, ${ }^{234} \mathrm{U} /{ }^{238} \mathrm{U}$ activity ratios, here denoted as $\left({ }^{234} \mathrm{U} /{ }^{238} \mathrm{U}\right)$ values) as a direct measure of the age of ice in syngenetic loess permafrost. U-series disequilibrium occurs over timescales of up to $10^{6} \mathrm{y}$, and results from several natural processes, either as a consequence of the distinct chemical behavior of different elements in the decay chain, or as a result of alpha-recoil effects from radioactive decay (Fig. 1) (Bourdon et al., 2003). Recoil-driven disequilibrium occurs as a function of rock-water contact at low temperature and has been extensively observed in groundwaters (Osmond et al., 1983; Paces et al., 2002; Porcelli and Swarzenski, 2003), as well as marine and riverine environments as a function of weathering (Vigier et al., 2001, 2006; Chabaux et al., 2003a,b, 2011; Robinson et al., 2004; Dosseto et al., 2006a,b, 2008, 2010; Pogge von Strandmann et al., 2011). Recoil effects have also been documented from mineral-ice contact (Fireman, 1986; Goldstein et al., 2004; Aciego et al., 2011) and in weathering rinds and soils (Pelt et al., 2008, 2013; Suresh et al., 2013). In general, recoil disequilibrium effects occur as a function of time, $\mathrm{U}$ concentrations in minerals and water or ice, and mineral grain size and surface area. Ice-rich loess permafrost that formed syngenetically with eolian loess deposition over time is an ideal substrate for testing a U-series age model for permafrost ice for four reasons. This variety of permafrost (1) should increase in age with depth (French and Shur, 2010; O'Donnell et al., 2011a), (2) should produce measureable signal due to small grain sizes and abundant mineral surfaces (Fireman, 1986; DePaolo et al., 2006, 2012; Maher et al., 2006; Bourdon et al., 2009), (3) should 


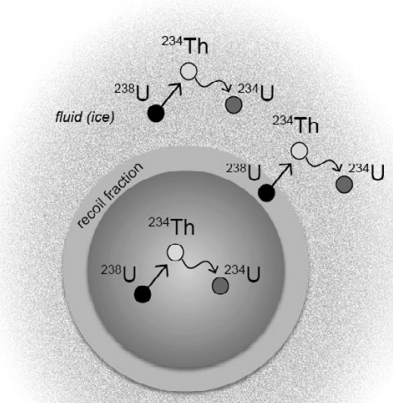

(a)

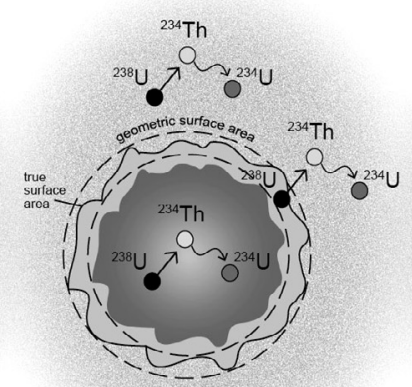

(b)

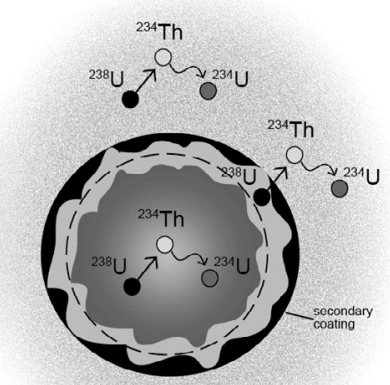

(c)

Fig. 1. Schematic illustration of radioactive decay of ${ }^{238} \mathrm{U}$ to ${ }^{234} \mathrm{U}$ in mineral grains and surrounding fluid (ice), including the recoil loss of ${ }^{234} \mathrm{Th}$ from (a) smooth grains, (b) grains with surface roughness, and (c) grains with surface roughness modified by secondary coatings. For silt-sized grains in loess, recoil loss of ${ }^{234} \mathrm{Th}$ (i.e., $\left({ }^{234} \mathrm{U} /{ }^{238} \mathrm{U}\right)<1$ ) will only be measurable at the grain rim due to the small recoil length $(30 \mathrm{~nm})$ relative to the radius of the grain. Modified from DePaolo et al. (2006); Aciego et al. (2011); Handley et al. (2013).

possess characteristic ice morphologies in support of its origin (French and Shur, 2010), and (4) should have a predictable mineral particle-size distribution and surface area as a result of sorting during eolian transport (Wright, 1995, 2001; Smalley et al., 2005). If present, weathering rinds may complicate interpretation of $\left({ }^{234} \mathrm{U} /{ }^{238} \mathrm{U}\right)$ values as a metric of time by adding surface area as well as $\mathrm{U}$ adsorbed from the surrounding fluid (Fig. 1) (Pelt et al., 2008; Suresh et al., 2013, 2014). While uncertainties of model ages based on $\left({ }^{234} \mathrm{U} /{ }^{238} \mathrm{U}\right)$ values in both sediment and ice can be substantial, their utility has been demonstrated (Dosseto et al., 2010; Aciego et al., 2011; Handley et al., 2013). Ultimately, the limited chronometric tools available for permafrost make the investigation of this approach worthwhile.

The objective of this work was to determine the utility of $\mathrm{U}$-series isotopes for modeling ages of permafrost ice and thaw waters. Development of this approach offers a means of tracking permafrost thaw dynamics in the context of both landscape history and the ongoing response of permafrost soils to global change. Recent work (Koch et al., 2013a) has suggested that $\left({ }^{234} \mathrm{U} /{ }^{238} \mathrm{U}\right)$ values can provide a signal of subsurface thaw in small catchments bounded by ice-rich loess and hosting ice wedge networks. We hypothesize that this signal will become increasingly evident in larger river systems such as the Yukon and its tributaries with loess dominated reaches as thaw increases in these previously resilient areas (Romanovsky et al., 2010; O'Donnell et al., 2011a, 2014; Kraemer and Brabets, 2012). With respect to landscape history, it has been argued that retreat from the last glacial maximum was underway by $25 \mathrm{ka}$ in the Brooks Range (Briner and Kaufman, 2008; Barclay et al., 2009). Large, inactive ice wedges in loess deposits have long been thought to be of late Pleistocene age. Subsequent warming and partial thaw of these features are indicated by flat tops several meters below the present land surface (Pewe, 1975). However, limitations of dating techniques applied to permafrost makes it difficult to evaluate these relationships. Preservation of Pleistocene permafrost through periods of warmer conditions would have depended on complex interactions among topography, water, soil, vegetation and snow over time (Jorgenson et al., 2010). Thus the current age and state of ground ice in upland loess deposits is both an indicator of landscape and ecosystem history, and a predictor of thaw susceptibility or resilience. Preservation of ground ice through major fluctuations in external climate conditions could provide important evidence of controls on boreal landscape evolution with climate, and has implications for landscape legacy effects on future thaw dynamics and carbon-mediated feedbacks with climate warming (Jorgenson et al., 2013a; Kanevskiy et al., 2014).

\section{MATERIALS AND METHODS}

To develop this U-series approach to dating ground ice, we (1) measured $\left({ }^{234} \mathrm{U} /{ }^{238} \mathrm{U}\right)$ values and $\mathrm{U}$ concentrations in waters from thawed segments of five deep (7-21 m) cores obtained in ice-rich loess permafrost, (2) measured $\left({ }^{234} \mathrm{U} /{ }^{238} \mathrm{U}\right)$ values and $\mathrm{U}$ concentrations in a sequence of leachates and residual solids following thaw of select samples within a single core, (3) quantified surface area of loess material in a subset of samples from a single core using direct measurement of surface area and inference from particle size distributions, (4) constrained near-surface ages using ${ }^{14} \mathrm{C}$ in thaw-water dissolved organic carbon (DOC) from select samples, and (5) used our results to constrain a geometric model of ice residence time based on $\left({ }^{234} \mathrm{U} /{ }^{238} \mathrm{U}\right)$ values (DePaolo et al., 2006; Lee et al., 2010; Aciego et al., 2011; Handley et al., 2013). Additionally, DOC concentrations in thaw waters provide a metric of carbon processing that is time dependent, and are expected to increase with depth and duration of ice preservation.

\subsection{Study site}

This work focuses on samples of permafrost (Fig. 2) formed in deep loess within the Hess Creek watershed near Livengood, Alaska (65.568N, 148.925W, NAD83), approx- 
imately $150 \mathrm{~km}$ north of Fairbanks, Alaska (Fig. 3). All core locations are on forested north-facing slopes underlain by permafrost, and are generally representative of black spruce ecosystems in the discontinuous permafrost zone of Alaska (Kane et al., 2005) and western Canada (Harden et al., 1997).

Interior Alaska is characterized by a continental climate, with temperature extremes ranging from $-50{ }^{\circ} \mathrm{C}$ to $+35^{\circ} \mathrm{C}$. In the Hess Creek area, the average daily air temperature ranges from $-25^{\circ} \mathrm{C}$ in January to $15^{\circ} \mathrm{C}$ in July. Annual precipitation averages $270 \mathrm{~mm}, 65 \%$ of which falls during the summer growing season (mid-May to early September). The cold snow period in interior Alaska is typically $>210$ days long with maximum snow accumulation at these sites (average $=44 \mathrm{~cm}$; see O'Donnell et al. (2011b)) occurring in late March (O'Donnell et al., 2011a).

In central Alaska, loess deposits vary widely in thickness, from a few $\mathrm{mm}$ to $>100 \mathrm{~m}$ (Pewe, 1975). In many upland locations, the downslope thickening of loess deposits has been interpreted as indicating re-transportation after eolian deposition, with accumulation on toeslopes and in valley bottoms (Pewe, 1975) - a process that would facilitate development of ground ice in addition to its burial and protection against thaw. Our study location captures this potential variation by evaluating depth trends along a hillslope using a sequence of cores that show increasing loess thickness downslope (ranging from 7 to $21 \mathrm{~m}$ thick; Fig. 4).

Most central Alaskan loess is glaciogenic, and formed during middle to late Pleistocene time (Pewe, 1975; Jensen et al., 2008, 2011; Muhs et al., 2008; Reyes et al., 2010b). The glacial source of loess for the study area was likely in the south-central Brooks Range to the north (Muhs and Budahn, 2006), where multiple glacial advances occurred during the Wisconsin period (12-110 ky BP) (Hamilton, 2001; Briner and Kaufman, 2008), and are associated with loess deposition (Hamilton, 1982). Greater loess production likely occurred in the region during full glacial climates; however, accumulation may have been reduced under those conditions due to changes in vegetation and surface processes related to increased aridity and decreased temperatures (Muhs et al., 2003). It is probable that loess originally generated in the Brooks Range may have been transported in the Yukon River and its tributaries prior to deposition at the Hess Creek site (Froese et al., 2005).

Vegetation plays a fundamental role in the formation and preservation of permafrost (Shur and Jorgenson, 2007). Vegetation at these sites is described by O'Donnell et al. (2011a) according to the Alaska Vegetation Classification System (Viereck et al., 1992). The dom-

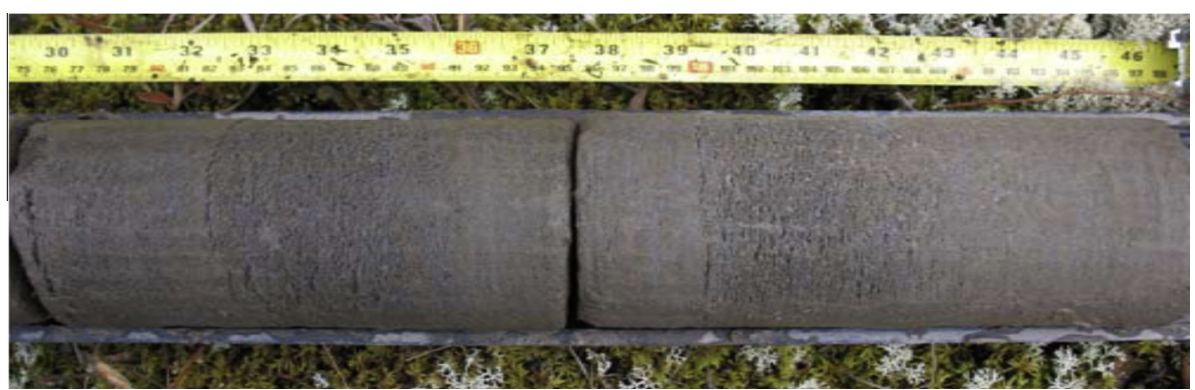

Fig. 2. Photo of core taken at an unburned site near Hess Creek (HCCN; O'Donnell et al., 2011a) showing syngenetic ice and redox banding.

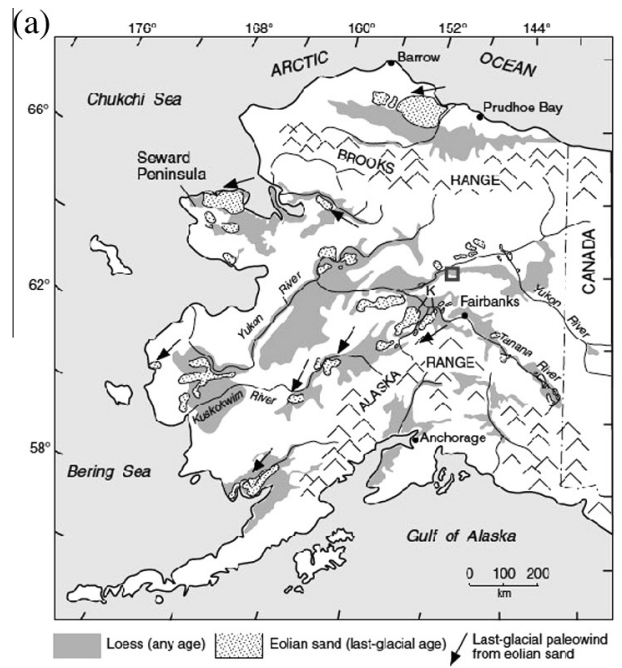

(b)

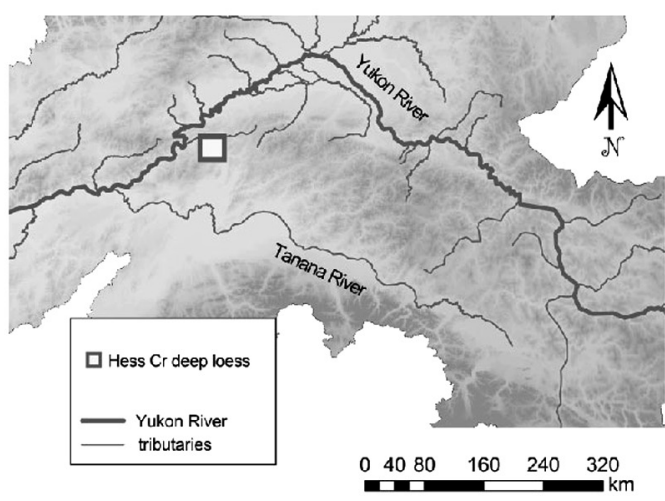

Fig. 3. Location of study site in central Alaska. (a) Location on Alaska loess map from Muhs and Budahn (2006); (b) location with respect to the Tanana and Yukon Rivers. 


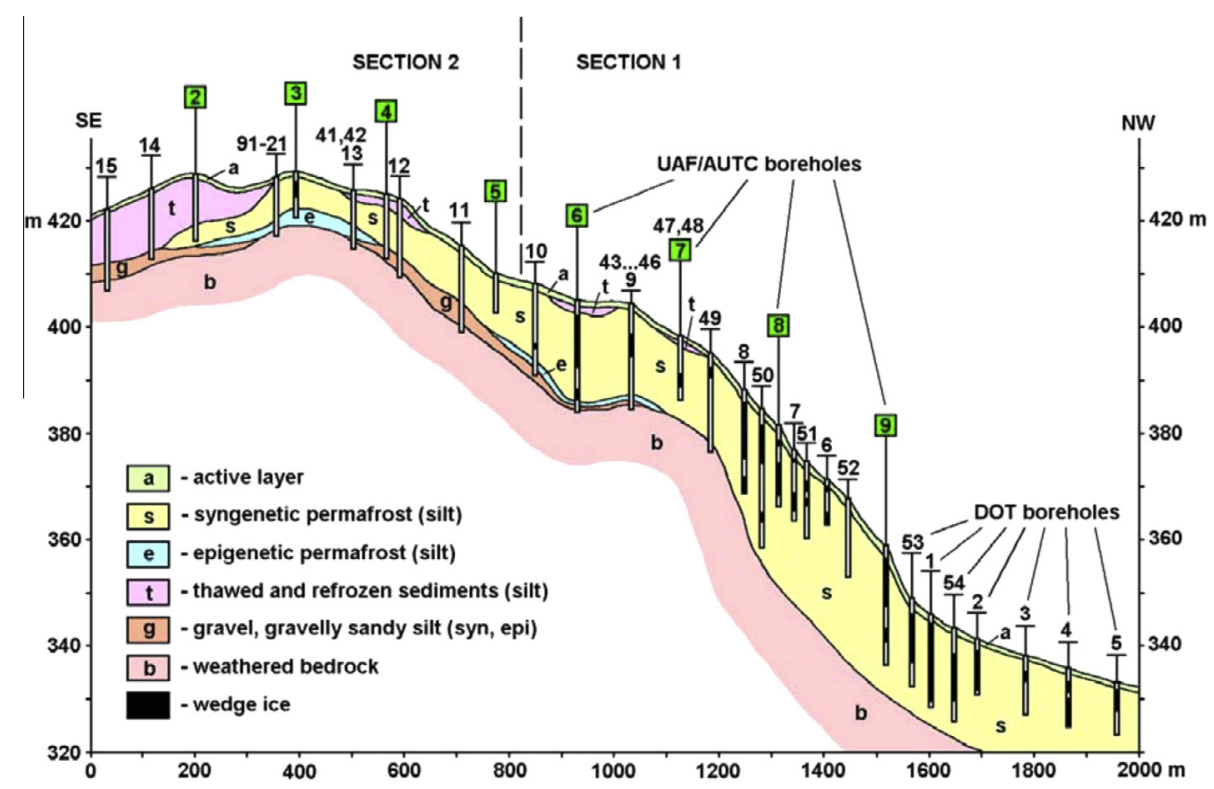

Fig. 4. University of Alaska Fairbanks/Alaska University Transportation Center (UAF/AUTC) core sequence (numbers 2 through 9 in green squares are referenced as cores A2 through A9 or HCDT.A2 through HCDT.A9 in this paper) (Shur et al., 2010). The hillslope profile illustrates loess (silt) distribution, wedge ice extent, and interpreted thaw zones based on reduced ice content. Additional Alaska Department of Transportation (DOT) boreholes are also indicated with underlined numbers; these boreholes were logged, but samples were not retained. Note $10 \times$ vertical scale exaggeration. Section 1 is distinguished by abundant wedge ice compared to Section 2 (Kanevskiy et al., 2012).

inant forest type on north-facing slopes of the Hess Creek region is open black spruce [Picea mariana (Mill.) B.S.P.]. In mature black spruce stands, the forest understory is composed of small woody shrubs, primarily Vaccinium vitis-idaea and Ledum groenlandicum. Feather mosses (Pleurozium schreberi and Hylocomium splendens), sphagnum (Sphagnum fuscum), and reindeer lichens (Cladonia stellaris and Cladonia arbuscula) dominate ground cover in these mature stands. In the recently burned black spruce stands, vegetation is dominated by standing dead $P$. mariana, and living $V$. vitis-idaea, Vaccinium uliginosum, L. groenlandicum, and Equisetum spp. Burned organic soil surfaces are colonized by Ceratodon purpureus in the recently burned stands. In ice-rich loess permafrost on upslope positions that might otherwise be more susceptible to thaw (Swanson, 1996), limited drainage upon thaw promotes permafrost resiliency and regrowth of organic horizons, further protecting these systems against warming climate conditions and increasing fire frequency (Shur and Jorgenson, 2007; O'Donnell et al., 2011a).

\subsection{Sample collection}

Porewaters were collected from soil pits excavated to the depth of frozen material in summers of 2008 and 2009 near coring locations. Solutions draining into pits were field filtered into acid-rinsed HDPE bottles using a $0.45 \mu \mathrm{m}$ capsule filter (Geotech, Inc.) and a peristaltic pump. Samples were transported on ice, acidified with $1.00 \mathrm{~mL}$ trace-metal grade $\mathrm{HNO}_{3}$, and refrigerated prior to analysis.

Subsamples from eight core sequences were analyzed in this study (Table 1). Five deeper core sequences represent a subset of those collected as part of the geotechnical investi- gation conducted in May 2008 by the University of Alaska, Fairbanks/Alaska University Transportation Center (UAF/AUTC) and the Alaska Department of Transportation and Public Facilities (AKDOT), in an effort to improve a section of the Dalton Highway near Livengood, Alaska (Fig. 4; Shur et al., 2010; Kanevskiy et al., 2012). Hollow stem drilling was conducted by AKDOT. Eight boreholes were cored by AKDOT and logged by AUTC scientists. The boreholes were drilled into and sometimes through the loess mantle overlying bedrock consisting of fractured Precambrian schist. Depths range from $7.5 \mathrm{~m}$ at the most upslope position, to $21.5 \mathrm{~m}$ at the most downslope position (Fig. 4). All cores were collected in an area that burned in 2003. All deep core sections were kept frozen in a portable freezer during collection and transportation back to the University of Alaska, Fairbanks.

In addition, subsections of three shallower cores $(\sim 2 \mathrm{~m})$ were collected in fall of 2007 at two adjacent convex upslope sites, one from a site that burned in 2003, and two from a "mature" site unburned in the last $\sim 100 \mathrm{y}$ (Table 1 ). These shallow cores were collected using a 7.5-cm-diameter core barrel (SIPRE corer) equipped with a hand-held powerhead, and are a subset of the burn chronosequence evaluated by O'Donnell et al. (2011a). A subsection of uppermost wedge ice was included in one "mature" site core. All subsections for U and DOC analysis were double bagged and transported on ice to Fairbanks, where they were stored frozen prior to shipment.

Subsections of the five deep cores (A2, A4, A5, A6, A9) and the three shallow cores were shipped frozen on dry ice to the USGS Denver Radiogenic Isotope Laboratory, where they were stored frozen prior to subsequent processing. 
Table 1

Uranium concentrations, ice content, and $\left(^{234} \mathrm{U} /{ }^{238} \mathrm{U}\right)$ values in thaw waters.

\begin{tabular}{|c|c|c|c|c|c|c|}
\hline Sample name ${ }^{a}$ & Sample mass, $\mathrm{g}$ & Ice content (thaw water), $g$ & [U], ppb & $\pm 2 \sigma, \mathrm{ppb}$ & $\left({ }^{234} \mathrm{U} /{ }^{238} \mathrm{U}\right)$ & $\pm 2 \sigma$ \\
\hline HCDT.A2.0885 & 280.03 & 103.93 & 10.480 & 0.043 & 1.224 & 0.007 \\
\hline HCDT.A2.0913 & 297.80 & 111.77 & 6.102 & 0.024 & 1.223 & 0.006 \\
\hline HCDT.A2.0931 & 272.36 & 111.93 & 4.255 & 0.015 & 1.214 & 0.005 \\
\hline HCDT.A2.0996 & 303.09 & 126.04 & 1.957 & 0.007 & 1.214 & 0.006 \\
\hline HCDT.A2.1016 & 212.05 & 108.60 & 1.661 & 0.007 & 1.184 & 0.009 \\
\hline HCDT.A4.0080 & 180.39 & 114.97 & 4.165 & 0.013 & 1.167 & 0.003 \\
\hline HCDT.A4.0116 & 146.69 & 89.41 & 7.430 & 0.024 & 1.170 & 0.004 \\
\hline HCDT.A4.0338 & 221.94 & 75.44 & 1.165 & 0.008 & 1.326 & 0.007 \\
\hline HCDT.A4.0445 & 193.01 & 78.86 & 3.400 & 0.019 & 1.264 & 0.011 \\
\hline HCDT.A4.0510 & 239.43 & 148.64 & 0.289 & 0.005 & 1.366 & 0.060 \\
\hline HCDT.A4.0645 & 224.68 & 120.87 & 0.477 & 0.003 & 1.508 & 0.009 \\
\hline HCDT.A4.0674 & 234.92 & 136.36 & 0.396 & 0.004 & 1.395 & 0.027 \\
\hline HCDT.A4.0750 & 247.10 & 144.54 & 3.143 & 0.013 & 1.360 & 0.007 \\
\hline HCDT.A4.0820 & 315.97 & 106.98 & 13.616 & 0.073 & 1.555 & 0.005 \\
\hline HCDT.A4.0857 & 308.93 & 122.50 & 12.545 & 0.041 & 1.491 & 0.006 \\
\hline HCDT.A5.0101 & 256.58 & 115.88 & 20.684 & 0.081 & 1.195 & 0.008 \\
\hline HCDT.A5.0361 & 264.93 & 134.39 & 2.551 & 0.034 & 1.373 & 0.078 \\
\hline HCDT.A5.0384 & 279.02 & 120.86 & 5.279 & 0.016 & 1.271 & 0.004 \\
\hline HCDT.A5.0437 & 233.28 & 111.26 & 8.506 & 0.028 & 1.261 & 0.006 \\
\hline HCDT.A5.0511 & 280.05 & 126.02 & 13.569 & 0.044 & 1.251 & 0.006 \\
\hline HCDT.A5.0545 & 164.34 & 99.70 & 5.872 & 0.019 & 1.248 & 0.005 \\
\hline HCDT.A5.0585 & 217.96 & 136.88 & 2.758 & 0.009 & 1.260 & 0.005 \\
\hline HCDT.A5.0627 & 259.30 & 165.88 & 5.424 & 0.020 & 1.273 & 0.007 \\
\hline HCDT.A5.0660 & 256.31 & 128.87 & 6.779 & 0.021 & 1.251 & 0.005 \\
\hline HCDT.A6.0151 & 304.63 & 133.98 & 1.981 & 0.008 & 1.173 & 0.005 \\
\hline HCDT.A6.1322 & 254.65 & 121.89 & 1.258 & 0.007 & 1.495 & 0.021 \\
\hline HCDT.A6.1380 & 264.74 & 120.78 & 2.040 & 0.008 & 1.502 & 0.011 \\
\hline HCDT.A6.1500 & 250.61 & 121.84 & 1.658 & 0.006 & 1.497 & 0.011 \\
\hline HCDT.A6.1560 & 252.29 & 102.14 & 17.915 & 0.057 & 1.379 & 0.004 \\
\hline HCDT.A6.1594 & 304.43 & 119.07 & 17.720 & 0.055 & 1.551 & 0.005 \\
\hline HCDT.A6.1762 & 218.32 & 153.48 & 6.765 & 0.022 & 1.271 & 0.005 \\
\hline HCDT.A9.0035 & 154.51 & 71.56 & 0.303 & 0.001 & 1.163 & 0.012 \\
\hline HCDT.A9.0055 & 205.34 & 111.23 & 2.105 & 0.008 & 1.168 & 0.014 \\
\hline HCDT.A9.0102 & 192.28 & 108.11 & 11.533 & 0.037 & 1.182 & 0.006 \\
\hline HCDT.A9.1102 & 188.63 & 104.25 & 0.584 & 0.003 & 1.322 & 0.037 \\
\hline HCDT.A9.1130 & 176.99 & 121.37 & 3.092 & 0.010 & 1.297 & 0.006 \\
\hline HCDT.A9.1237 & 185.63 & 79.56 & 46.453 & 0.149 & 1.386 & 0.010 \\
\hline HCDT.A9.1315 & 196.59 & 101.16 & 1.532 & 0.008 & 1.468 & 0.014 \\
\hline HCDT.A9.1399 & 294.11 & 97.01 & 34.294 & 0.105 & 1.366 & 0.004 \\
\hline HCDT.A9.1695 & 226.43 & 100.31 & 12.351 & 0.040 & 1.366 & 0.004 \\
\hline HCDT.A9.1715 & 258.16 & 104.25 & 10.115 & 0.031 & 1.716 & 0.006 \\
\hline HCDT.A9.1770 & 275.16 & 134.38 & 3.973 & 0.013 & 1.703 & 0.005 \\
\hline HCDT.A9.1849 & 306.28 & 122.65 & 7.097 & 0.023 & 1.529 & 0.007 \\
\hline HCDT.A9.1879 & 178.78 & 32.84 & 4.477 & 0.015 & 1.594 & 0.008 \\
\hline HCDT.A9.1924 & 237.93 & 128.51 & 1.867 & 0.007 & 1.772 & 0.011 \\
\hline HCDT.A9.1956 & 283.01 & 109.07 & 4.532 & 0.015 & 1.904 & 0.014 \\
\hline HCDT.A9.1977 & 218.94 & 132.12 & 1.790 & 0.006 & 1.768 & 0.007 \\
\hline HCDT.A9.2005 & 166.39 & 96.03 & 1.019 & 0.004 & 1.655 & 0.011 \\
\hline HCDT.A9.2050 & 197.35 & 121.39 & 1.003 & 0.004 & 1.638 & 0.016 \\
\hline HCDT.A9.2069 & 206.79 & 124.10 & 1.482 & 0.007 & 1.589 & 0.017 \\
\hline HCDT.A9.2114 & 317.79 & 130.63 & 3.559 & 0.011 & 1.541 & 0.018 \\
\hline HCCN.1.053 ${ }^{\mathrm{b}}$ & 382.60 & 190.76 & 3.525 & 0.018 & 1.163 & 0.006 \\
\hline HCCN.1.119 & 379.22 & 115.02 & 17.187 & 0.054 & 1.162 & 0.003 \\
\hline HCCN.1.150 & 386.88 & 30.63 & 41.964 & 0.133 & 1.166 & 0.004 \\
\hline HCCN.2.127 & 280.44 & 68.63 & 31.729 & 0.097 & 1.165 & 0.003 \\
\hline HCCN.2.165 & 323.43 & 66.01 & 35.706 & 0.108 & 1.169 & 0.003 \\
\hline HCCN.2.185 & 313.40 & 32.88 & 24.792 & 0.078 & 1.188 & 0.003 \\
\hline HCCN.2.205 & 294.51 & 196.68 & 0.286 & 0.001 & 1.180 & 0.006 \\
\hline HCCN.2.255 & 327.90 & 98.49 & 0.094 & 0.0004 & 1.210 & 0.008 \\
\hline HC03.5.060 & 345.01 & 144.00 & 5.466 & 0.020 & 1.196 & 0.006 \\
\hline HC03.5.112 & 386.40 & 26.65 & 12.968 & 0.042 & 1.203 & 0.004 \\
\hline
\end{tabular}


${ }^{\text {a }}$ Last four digits of HCDT sample numbers and last three digits of $\mathrm{HCCN}$ and $\mathrm{HC} 03$ sample numbers indicate depth in $\mathrm{cm}$. Sites HCCN.1 and HCCN.2 are within one kilometer of HCDT sites (deep cores); both HC03.5 and HCDT burned in 2003.

${ }^{\mathrm{b}}$ Analyzed in duplicate for $\left({ }^{234} \mathrm{U} /{ }^{238} \mathrm{U}\right)$; uncertainties reflect propagation for two analyses.

\subsection{Core description and interpretation}

Detailed description of cryostructures in the cores followed methods of Shur et al. (2010) and Kanevskiy et al. (2011), and are given in Kanevskiy et al. (2012). This evaluation concluded that the permafrost was primarily formed syngenetically with loess deposition during Pleistocene time (Shur et al., 2010; Kanevskiy et al., 2012). The upslope cores were generally more ice-poor, while the down-slope cores were more ice-rich, with abundant wedge ice (Figs. 4 and 5). This suggests better preservation of ground ice in the downslope positions.

Stratigraphic descriptions and ice contents of the deep cores revealed two major stratigraphic units related to timing of ground-ice development (Kanevskiy et al., 2012). An ice-poor unit of variable thickness near the surface provides evidence of partial thaw and re-freezing (unit labeled $t$ in Figs. 4 and 5). Core A2 is mainly ice-poor (gravimetric water content $\sim 40 \%$ ) at $2-9 \mathrm{~m}$ depth, core A4 is ice-poor $(40-50 \%)$ at $1.5-3.0 \mathrm{~m}$ depth, and core A6 is ice-poor $(\sim 40 \%)$ at $1-3 \mathrm{~m}$ depths. Cryostructures within this unit are mainly nonvisible to visible pore ice. Below this zone, the cores typically have higher ice contents including mmscale cryostructures ranging from micro-lenticular to micro-ataxitic, as well as cm-scale "belts". Ice contents in this ice-rich zone are higher, with values typical for syngenetic permafrost (50-200\% gravimetric moisture content). Ice wedges were frequently encountered in the cores (up to $47 \%$ of the total volume) and persisted with depth, strongly suggesting preservation following upward propagation of wedges with loess accumulation. Cores A6, A7 and A9 are in the downslope "ice-rich" zone of increasing loess depth and ice-wedge frequency downslope (Figs. 4 and 5).

Permafrost genesis within the core sequence is interpreted to be both syngenetic and quasi-syngenetic (French and Shur, 2010; Shur et al., 2010). Syngenetic permafrost forms in response to simultaneous sedimentation that causes the top of the permafrost table to propagate upwards, with volumetric expansion (200\% and more) due to ice aggradation, as well as high organic matter content, characteristic cryostructures, and frequent ice wedges. At shallower depths above or in the absence of ice wedge sequences (e.g., core A4), ice-rich zones may indicate formation of "quasi-syngenetic" permafrost by virtue of post-fire moss re-growth or downslope sedimentation processes that provide the thermal insulation needed for upward re-propagation of an ice-rich permafrost table (Shur and Jorgenson, 2007).

We hypothesize that the layer of frozen material overlying flat-topped ice wedges along the hillslope reflects the depth affected by more frequent thaw, and some degree of downslope sediment transport and water movement. This process could result in age inversion of the solid-phase carbon and possible homogenization of the $U$ series signal with depth due to an overall mixing caused by thawing and refreezing of aqueous fractions. However, this effect notably was not observed in ${ }^{14} \mathrm{C}$ profiles of neighboring

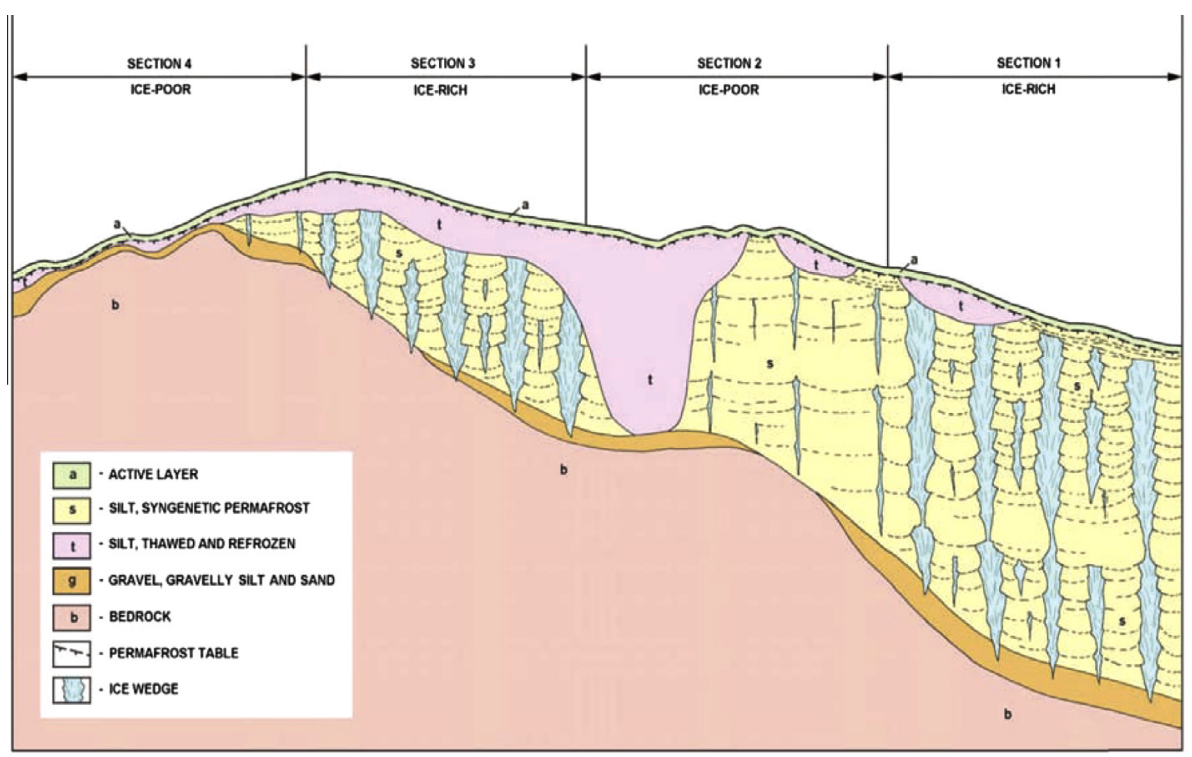

Fig. 5. Interpolated subsurface ice wedge and thaw zone distribution based on AUTC/DOT cores (Shur et al., 2010; Kanevskiy et al., 2012). Zones of lesser thaw (less reduction in ice content) also suggested by flat tops on ice wedge sequences. Note that the area shown is expanded compared to Fig. 4. 
shallow cores (O'Donnell et al., 2011a). The upslope icepoor/thaw zones, downslope thickening of accumulated loess and downslope increase in ice-wedge frequency could reflect the combined processes of downslope sediment redistribution, upslope thaw-water loss, and downslope water accumulation and ice aggradation. Sediment transport is further indicated by interlayering of gravels in downslope cores $\mathrm{A} 7$ and $\mathrm{A} 8$, and burial of ice-rich intermediate layer in core A7. The absence of an ice-rich intermediate layer at the top of the permafrost table in cores A6 and A7 (whereas an ice-rich intermediate layer is present in cores A3, A4 and A5, as well as A8 and A9) indicates a limited timeframe of slope stability at the midslope positions. However, slope angles of 2-8 degrees suggest limited potential for downslope movement following previous redistribution (Wu, 1984; Carey and Woo, 2002), although ongoing solifluction may occur (Harris et al., 2008).

\subsection{Thaw water separation and analysis}

Selected subsections of frozen UAF/AUTC cores 2, 4, 5, 6 and 9 (A2, A4, A5, A6 and A9; Fig. 4; Table 1) were placed in pre-weighed polypropylene jars, and weighed to ensure accurate evaluation of total mass. Core sections were thawed in the jars at room temperature and the resulting slurry was transferred in aliquots to $50-\mathrm{mL}$ centrifuge tubes, which were then centrifuged at $10,000 \mathrm{rpm}$ for $10 \mathrm{~min}$. The supernatant was transferred by pipet into a separate tube, and filtered through a $0.45 \mu \mathrm{m}$ glass fiber filter. The solids were oven-dried overnight at $105^{\circ} \mathrm{C}$, except for the portions used in the leaching experiment.

\subsection{Solid phase analysis}

Evolution of $\left({ }^{234} \mathrm{U} /{ }^{238} \mathrm{U}\right)$ disequilibrium over time depends on (1) $U$ distribution in the solid and surrounding water/ice, and (2) total particle surface area subject to recoil loss. Following initial analysis that revealed increasing $\left({ }^{234} \mathrm{U} /{ }^{238} \mathrm{U}\right)$ values with depth, we undertook quantification of $U$ distribution in a subset of samples from core A4, using simple leaching steps based on prior work (Maher et al., 2006; Lee et al., 2010). We also evaluated total particle size distribution and Brunauer-Emmett-Teller (BET) surface area in a subset of samples from core A9 as a test of their influence on $\left({ }^{234} \mathrm{U} /{ }^{238} \mathrm{U}\right.$ ) values (DePaolo et al., 2006; Maher et al., 2006).

\subsubsection{Leaching experiment}

In order to evaluate the total distribution of $U$ in recoil-affected samples showing a range of $\left({ }^{234} \mathrm{U} /{ }^{238} \mathrm{U}\right)$ values, we conducted leaching experiments using a subset of samples from 1 to $9 \mathrm{~m}$ depth in core A4. This core was selected early in the study because $\left({ }^{234} \mathrm{U} /{ }^{238} \mathrm{U}\right)$ values in its thaw waters increased dramatically over a relatively short depth interval $(\sim 8 \mathrm{~m})$. The leach sequence was intended to provide a simple evaluation of the amount and isotopic composition of $U$ retained in secondary coatings on particles (e.g., carbonate, iron oxide, organics), as well as the amount and isotopic composition of $U$ in the residual solid. By measuring $\left({ }^{234} \mathrm{U} /{ }^{238} \mathrm{U}\right)$ values in all leachates and residues in these samples, we attempted to limit the uncertainties inherent in procedurally defined leaching steps, although in future studies, buffered solutions and particle sizing would be preferred (Lee et al., 2010; Handley et al., 2013; Suresh et al., 2014). Our aim was simply to capture $U$ that might be present in highly exchangeable sites, sorbed tightly onto mineral surfaces, or present in organic complexes.

About $2 \mathrm{~g}$ of wet solids from each of six samples (core A4) were subjected to a series of leaches including: (1) ultrapure water, (2) trace metal grade $1 \mathrm{~N} \mathrm{HCl}$, and (3) a second round of $1 \mathrm{~N} \mathrm{HCl}$ following ashing for $1 \mathrm{~h}$ at $550{ }^{\circ} \mathrm{C}$ (to combust organic carbon). This procedure was selected for simplicity based on a trial run in which substantial $U$ ( $200 \mathrm{ng} \mathrm{g}^{-1}$ solid) was released with $1 \mathrm{~N} \mathrm{HCl}$ before and after combustion. Leaching solutions were shaken with solids in $50-\mathrm{mL}$ centrifuge tubes for $30 \mathrm{~min}$, then centrifuged at $10,000 \mathrm{rpm}$ for $10 \mathrm{~min}$. The supernatant was separated and one aliquot was dried for $\mathrm{U}$ purification and isotope analysis. The remaining aliquot was acidified using Optima grade $\mathrm{HNO}_{3}$ and analyzed for trace-element concentrations by quadrupole ICP-MS. The solids were digested in a mixture of hot $\left(\sim 200{ }^{\circ} \mathrm{C}\right)$, concentrated $\mathrm{HF}$ and $\mathrm{HNO}_{3}$ and analyzed for $\mathrm{U}$ isotopes.

\subsubsection{Particle size distribution and surface area}

In order to test the effect of surface area on thaw-water $\left({ }^{234} \mathrm{U} /{ }^{238} \mathrm{U}\right)$ values with depth, we measured particle-size distributions and specific surface area in a subset of samples from depths of 1 to $21 \mathrm{~m}$ in core A9. This core was selected because it contained the greatest range and oscillation in thaw-water $\left({ }^{234} \mathrm{U} /{ }^{238} \mathrm{U}\right)$ values. In addition to constraining the surface areas used to model ages, we wanted to explore the degree to which variations in the overall $\left({ }^{234} \mathrm{U} /{ }^{238} \mathrm{U}\right)$-depth trend might be explained by variation in particle size distribution and hence surface area.

Five loess samples from core A9 were evaluated for specific surface area (SSA) by whole-sample BET analysis using a Micrometrics $^{\mathrm{TM}}$ TriStar II 3020 Automatic Physisorption Analyzer at the University of Minnesota. After initial SSA analysis of untreated soil, organic matter was removed from the same samples by heating in a muffle furnace at $350{ }^{\circ} \mathrm{C}$ for $12 \mathrm{~h}$ (Wagai et al., 2009). Following heating, samples were then subject to the same SSA analysis. Particle size distribution (PSD) in the same samples was determined using a Malvern particle-size analyzer at the USGS Geosciences and Environmental Change Science Center soils lab in Denver, with and without treatment for carbonate using acetic acid, and organic matter using hydrogen peroxide. The fractional volume of particles in each of fifty size bins ranging from 0.06 to $2000 \mu \mathrm{m}$ diameter was determined. PSD and BET results were used to calculate recoil loss fractions $\left(f_{\alpha}\right)$ as further described below.

\section{6. $U$ concentrations and isotopic analysis}

Leach solutions, porewaters and dissolved residues were initially analyzed for U concentration by quadrupole ICPMS. Precise U concentrations and isotopic compositions 
were then determined by isotope dilution and thermal-ionization mass spectrometry. Aliquots containing $~ 100 \mathrm{ng} \mathrm{U}$ were weighed into $15-\mathrm{mL}$ Teflon vials, acidified with 20 drops ultrapure concentrated $\mathrm{HNO}_{3}$, spiked with a highly purified isotope tracer solution containing about $2 \mathrm{ng}$ ${ }^{236} \mathrm{U}$, and equilibrated overnight at sub-boiling temperatures. Spike addition allowed for very precise quantification of $U$ concentrations, and evaluation of yields following the purification procedure. Solutions were equilibrated, dried, and re-dissolved in $0.5 \mathrm{~mL} 7 \mathrm{~N}^{-} \mathrm{HNO}_{3}$.

For the core-sample thaw waters, $5-20 \mathrm{~mL}$ of thaw water were weighed into a pre-cleaned quartz crucible, acidified with 20 drops ultrapure, concentrated $\mathrm{HNO}_{3}$, and spiked with about $2 \mathrm{ng}$ of ${ }^{236} \mathrm{U}$ tracer solution. The solution was dried on a hotplate in a clean hood and then heated in a muffle furnace at $550{ }^{\circ} \mathrm{C}$ for $1 \mathrm{~h}$ to remove organic compounds. The remaining solid was dissolved in $7 \mathrm{~N} \mathrm{HNO}_{3}$ (trace metal grade), transferred to a $15-\mathrm{mL}$ Teflon vial (Savillex Corporation $^{\mathrm{TM}}$ ) and dried. The portion not soluble in $7 \mathrm{~N} \mathrm{HNO}_{3}$ was dissolved in 10-30 drops of concentrated $\mathrm{HF}$, dried, redissolved in $7 \mathrm{~N} \mathrm{HNO}_{3}$, and combined with the previously dissolved portion of the sample for a final volume of $\sim 1 \mathrm{~mL}$ in $7 \mathrm{~N} \mathrm{HNO}_{3}$.

Following dissolution in $7 \mathrm{~N} \mathrm{HNO}_{3}$, uranium salts were purified using standard ion exchange chemistry with AG 1$\mathrm{X} 8$ resin (200-400 mesh) and $7 \mathrm{~N} \mathrm{HNO}_{3}$ followed by $6.5 \mathrm{~N}$ $\mathrm{HCl}$ acid prior to elution of $\mathrm{U}$ using $0.05 \mathrm{~N} \mathrm{HNO}_{3}$. Purified $\mathrm{U}$ salts were evaporated onto one side of a double-Re filament assembly and analyzed using a ThermoFinnigan Triton mass spectrometer equipped with a secondary electron multiplier (SEM) and retarding potential quadrapole (RPQ) electrostatic filter allowing abundance sensitivity measured at mass 237 of approximately 20 parts per billion. Measurements were made using the single SEM in dynamic peakjumping mode on ${ }^{233} \mathrm{U},{ }^{234} \mathrm{U},{ }^{235} \mathrm{U}$, and ${ }^{236} \mathrm{U}$. Atomic ratios of ${ }^{234} \mathrm{U} /{ }^{238} \mathrm{U}$ were derived using the measured ${ }^{234} \mathrm{U} /{ }^{235} \mathrm{U}$ ratio and an assumed ${ }^{238} \mathrm{U} /{ }^{235} \mathrm{U}$ ratio of 137.88 (Steiger and Jager, 1977) and converted to activity ratios $\left(\left({ }^{234} \mathrm{U} /{ }^{238} \mathrm{U}\right)\right.$ values $)$ using published values for decay constants for ${ }^{234} \mathrm{U}\left(2.8262 \times 10^{-6} \mathrm{y}^{-1}\right)($ Cheng et al., 2000) and ${ }^{238} \mathrm{U}\left(1.55125 \times 10^{-10} \mathrm{yr}^{-1}\right)($ Jaffey et al., 1971). All measurements were corrected for spike contributions, mass fractionation, and blank contribution, and were normalized to the accepted value of $5.29 \pm 0.04 \times 10^{-5}( \pm 2 \sigma)$ for ${ }^{234} \mathrm{U} /{ }^{238} \mathrm{U}$ in NIST SRM 4321B, which was included with each barrel of unknown samples. Two hundred sixty nine analyses of the SRM 4321B standard determined over a period from 2007 to 2012 yielded an average ${ }^{234} \mathrm{U} /{ }^{238} \mathrm{U}$ atomic ratio of $5.2891 \times 10^{-5}\left(2 \times\right.$ standard deviation $=0.0098 \times 10^{-5}$, and $2 \times$ standard error of the mean $=0.0006 \times 10^{-5}$ ). Seventy one analyses of an in-house standard assumed to be in secular equilibrium (solution of 69.3-Ma $\mathrm{U}$ ore from the Schwartzwalder mine) (Ludwig et al., 1985) analyzed over same period yielded an average $\left({ }^{234} \mathrm{U} /{ }^{238} \mathrm{U}\right)$ of 0.9982 with $2 \times$ standard deviation of 0.0024 and a $2 \times$ standard error of the mean of 0.0003 . Full procedural blanks typically contained between 5 and $50 \mathrm{pg} \mathrm{U}$ and constituted a small fraction of total $\mathrm{U}$ from the sample, which typically ranged between 11 and $1740 \mathrm{ng} \mathrm{U}$.

\subsection{DOC concentration and isotopic analysis}

To test the age model for permafrost based on $\left({ }^{234} \mathrm{U} /{ }^{238} \mathrm{U}\right)$ values, we evaluated ${ }^{14} \mathrm{C}$ ages of DOC in six samples from three cores. DOC concentrations in all filtered thaw waters were determined using an OI Analytical Model $700^{\mathrm{TM}}$ total organic carbon analyzer via a platinum-catalyzed persulfate wet oxidation method (Aiken, 1992). In the samples selected for ${ }^{14} \mathrm{C}$ analysis, DOC concentrations were also determined by UV-oxidation. UV-oxidation was performed using a UV system that was directly connected to vacuum lines where the resulting $\mathrm{CO}_{2}$ was cryogenically purified for ${ }^{14} \mathrm{C}$ and $\delta^{13} \mathrm{C}$ analysis using methods described in detail elsewhere (Raymond and Bauer, 2001; Raymond et al., 2004). Briefly, a thaw water subsample containing $\sim 0.1 \mathrm{mg}$ DOC was transferred to a clean quartz tube. The samples were acidified with $0.2 \mathrm{~mL}$ of ultra-high-purity $40 \%$ phosphoric acid. The samples were then sparged with ultra-high-purity (UHP) $\mathrm{N}_{2}$ to remove any inorganic carbon. UHP $\mathrm{O}_{2}$ was then sparged through the system to provide an oxidant for the UV oxidation of DOC. The sample was then oxidized with UV. The resulting $\mathrm{CO}_{2}$ was transferred to the vacuum line and cryogenically purified. The purified $\mathrm{CO}_{2}$ was graphitized and analyzed for carbon isotopes at the National Ocean Sciences Accelerator Mass Spectrometer at the Woods Hole Oceanographic Institution. Full procedural blanks were below the detection limit for DOC $(\sim 0.05 \mathrm{ppm})$. DOC concentrations determined by the two methods differed by $1-10 \%$.

\section{8. $\mathrm{U}$ series age model}

To estimate the age of ground ice in each sample, we combined measured $\left({ }^{234} \mathrm{U} /{ }^{238} \mathrm{U}\right)$ values, $\mathrm{U}$ concentrations, and particle-size distributions with a geometric model of $\left({ }^{234} \mathrm{U} /{ }^{238} \mathrm{U}\right)$ evolution in ice and solids with time (Fireman, 1986; DePaolo et al., 2006; Maher et al., 2006; Lee et al., 2010; Aciego et al., 2011; Handley et al., 2013). Geologic materials older than about $1 \mathrm{Ma}$ that have not interacted with migrating solutions will have $\left({ }^{234} \mathrm{U} /{ }^{238} \mathrm{U}\right)$ values of 1.000 , a state defined as secular equilibrium (see e.g., Bourdon et al., 2003). If the solid material is permeable, fractured, or reduced to smaller particles, the resulting surface area is subject to radioactive disequilibrium as a result of recoil processes associated with alpha decay of ${ }^{238} \mathrm{U}$. As a result, ${ }^{234} \mathrm{U}$ is enriched in the solution because of either direct ejection of daughter isotopes from the mineral completely, or preferential leaching of ${ }^{234} \mathrm{U}$ from radiation-damaged crystal lattice sites (Gascoyne, 1992; Andersen et al., 2009). In either case, evolution of the disequilibrium signal occurs as a function of particle surface area, fluid residence time, and the relative concentration of $U$ in the fluid versus the mineral solid (Osmond and Cowert, 2000; Porcelli and Swarzenski, 2003). Central Alaskan loess is primarily $(>65 \%)$ composed of silt-sized grains of quartz, plagioclase, mica and chlorite (Muhs et al., 2003; Muhs and Budahn, 2006), and is suited for U series modeling due to its relatively small sized mineral grains with high surface area. 
For this work, a geometric model provided a relatively simple approach to modeling $U$ series data as an indicator of ice-loess interaction time (DePaolo et al., 2006; Maher et al., 2006; Bourdon et al., 2009; Dosseto et al., 2010; Lee et al., 2010; Aciego et al., 2011; Handley et al., 2013). In that model, the value $f_{\alpha}$ is the fraction of ${ }^{238} \mathrm{U}$ decays that should result in the ejection of the immediate daughter ${ }^{234} \mathrm{Th}$ atom from the grain due to the proximity of the decay site to the mineral surface (i.e., within the $\alpha$-recoil distance of $30 \mathrm{~nm}$ for most silicates) (Maher et al., 2006; Lee et al., 2010; Handley et al., 2013). The ejected ${ }^{234}$ Th atom then undergoes rapid beta decay (half life $=24.1$ days) to ${ }^{234} \mathrm{U}$.

The magnitude of $f_{\alpha}$ is a function of recoil length $(L)$ and surface area $(S)$. For samples with surface areas measured by BET, $f_{\alpha}$ values were calculated directly using (Kigoshi, 1971; DePaolo et al., 2006; Maher et al., 2006; Lee et al., 2010; Handley et al., 2013):

$f_{\alpha}=\frac{1}{4} L S \rho_{s}$

where $S$ is measured surface area $\left(\mathrm{m}^{2} \mathrm{~g}^{-1}\right)$ and $\rho_{S}$ is the particle density (estimated as $2.69 \mathrm{~g} \mathrm{~m}^{-3}$ ). It has been argued that small-scale roughness included in direct measurement of surface area (that is, at the scale of gas molecules used to make the measurement) require use of a fractal dimension to calculate $f_{\alpha}$ values (Bourdon et al., 2009; Lee et al., 2010; Handley et al., 2013); the resulting $f_{\alpha}$ values are typically an order of magnitude smaller and the model ages consequently greater. Here, we use Eq. (1) as a conservatively high estimate of $f_{\alpha}$ for calculation of minimum ice age.

For samples without surface area measurements, values of $f_{\alpha}$ for different particle size categories were calculated assuming spherical particles of radius $r(\mathrm{~m})$ (Kigoshi, 1971):

$f_{\alpha, r}=\frac{3}{4}\left(\frac{L}{r}-\frac{L^{3}}{12 r^{3}}\right)$

where $r$ was assigned as the modal value for each of the 50 measured particle-size bins. These $f_{\alpha, r}$ values were multiplied by volume fractions in each size bin $\left(X_{r}\right)$, as well as a factor representing surface roughness $\left(\lambda_{r}\right)$ and an aspect ratio $\left(\beta_{r}\right)$, and summed to obtain an initial value $f_{\alpha, S}$ for each sample (DePaolo et al., 2006; Maher et al., 2006; Dosseto et al., 2010; Lee et al., 2010):

$f_{\alpha, s}=\sum_{r=\min }^{r=\max } f_{\alpha, r} X_{r} \beta_{r} \lambda_{r}$

Based on previous work, a value of $\beta_{r} \lambda_{r}=10$ was used to evaluate the combined effects of aspect ratio and surface area (DePaolo et al., 2006, 2012; Lee et al., 2010; Handley et al., 2013). Four of the 51 size categories consisting of particles $<0.54 \mu \mathrm{m}$ in diameter were assigned progressively lower values of $\beta_{r} \lambda_{r}(8-2)$ so that their $f_{\alpha, r}$ values would not exceed 1.0.

Using this geometric approach, the activity ratio of the solid for a given age $\left(A_{s, t}\right)$ is (DePaolo et al., 2006, 2012; Maher et al., 2006; Lee et al., 2010):

$A_{s, t}=\left(1-f_{\alpha}\right)+\left[A_{s, i}-\left(1-f_{\alpha}\right)\right] e^{-\lambda_{234} t}$ where $A_{s, i}$ is the initial activity ratio of the sediment or loess (which approaches an equilibrium value of $\left(1-f_{\alpha}\right)$ ), $\lambda_{234}$ is the decay constant of ${ }^{234} \mathrm{U}\left(\mathrm{y}^{-1}\right)$ and $t$ is time (y), or the "comminution age" of the solid, meaning the total time since the sediment was generated, regardless of transport history (DePaolo et al., 2006, 2012; Lee et al., 2010). If $A_{s, i}$ is considered as the activity of the loess upon deposition, this equation describes the measured activity of the loess as a function of time since deposition. However the activity of loess particles upon deposition is not usually assessable. Eq. (4) can be rearranged to solve for $t$ as a function of $A_{s, i}$ and the solid at time $t\left(A_{s, \mathrm{t}}\right)$ :

$t_{\text {solid }}=-\left(\frac{1}{\lambda_{234}}\right) \ln \left[\frac{A_{s, t}-\left(1-f_{\alpha}\right)}{A_{s, i}-\left(1-f_{\alpha}\right)}\right]$

where $\left(A_{s, i}\right)>\left(A_{s, t}\right)>\left(1-f_{\alpha}\right)$. This age equation relies only on evolution of the mineral phase and does not assume closed-system evolution with the surrounding fluid (ice). For glaciogenic loess accumulation in ice-rich syngenetic permafrost, the activity ratio of the original loess $\left(A_{s, i}\right)$ may have been close to unity (DePaolo et al., 2012), and transport times arguably were short before particles were encapsulated in ice rich permafrost. Here, because our focus is the time the loess has spent in permafrost, we consider values of $A_{s, i}$ as the activity of the loess upon deposition, following transport times from the Brooks Range that are unknown, but were likely brief (Muhs and Budahn, 2006).

Alternately an age equation can be derived from the geometric model that describes time evolution of the disequilibrium signal in the surrounding ice/fluid (Fireman, 1986; Aciego et al., 2011), based only on activity ratios in ice and initial water, the recoil fraction, and the distribution of $\mathrm{U}$ between solids and thaw water. This age equation for ice assumes a closed system and can be expressed in terms of activity ratios as:

$t_{\text {ice }}=-\left(\frac{1}{\lambda_{234}}\right) \ln \left[\frac{A_{f, t}-f_{\alpha} R_{s}-1}{A_{f, i}-f_{\alpha} R_{s}-1}\right]$

where $R_{s}$ is the ratio of $\left({ }^{238} \mathrm{U}\right)$ in the solid to $\left({ }^{238} \mathrm{U}\right)$ in the ice $\left(X_{s} / X_{f}\right)$ and $X_{s}=1-X_{f}$.

Application of Eq. (6) requires knowledge of the distribution of $\mathrm{U}$ in the solid $\left(X_{S}\right)$ compared to the fluid $\left(X_{f}\right)$. With analysis of both thaw water and solids in these cores, an assessment of assumptions about starting values in the mineral phase can be undertaken. Initially the massweighted total would reflect the activity ratio of the starting loess $\left(A_{S, i}\right)$ and the porewater from which the ice developed $\left(A_{f, i}\right)$ :

$A_{s+f, i}=A_{s, i} X_{s}+A_{f, i} X_{f}$

where $X_{s}$ is the fraction of total $\mathrm{U}$ in the solid and $X_{f}$ is the fraction of total $U$ in the ice (which may contain a liquid component). Under closed system conditions (no removal of ice or water with thaw), the evolution of the massweighted total $\left({ }^{234} \mathrm{U} /{ }^{238} \mathrm{U}\right)$ in the permafrost core based on activity in the mineral solid $\left(A_{s, t}\right)$ and fluid (ice and water, $A_{f, t}$ ) would occur congruently, summing to the value of $A_{s+f, t}$ : 
$A_{s+f, t}=A_{s, t} X_{s}+A_{f, t} X_{f}$

Here a key assumption requiring exploration in future research is that the $U$ distribution is constant over the time of freezing, and equal to values derived in the leaching experiment. In addition, we assume that the permafrost developed from active layer porewater with a $\left({ }^{234} \mathrm{U} /{ }^{238} \mathrm{U}\right)$ value of 1.161 , estimated from the average of three analyses of active-layer porewater collected nearest the core site (Erickson Creek samples in Table 2). Assuming a closed system, the age equation for the combined liquid and solid would be:

$A_{s+f, t}=A_{s+f, i} e^{-\lambda_{234} t}$

$t_{\text {closed }}=-\left(\frac{1}{\lambda_{234}}\right) \ln \left[\frac{A_{s+f, t}}{A_{s+f, i}}\right]$

Based on results from our leaching experiment, we assume that leachable fractions with values of $\left({ }^{234} U /{ }^{238} U\right)>1$ represent components of the "fluid" fraction with a value identical to that observed in the thaw water. This assumption is not tested here but is supported by work demonstrating that weathering rinds reflect the composition of weathering fluids and concentrate U (Pelt et al., 2008; Andersen et al., 2009). To our knowledge, the character of weathering rinds in permafrost and the effect of weathering rinds on closed system evolution of $\left({ }^{234} \mathrm{U} /{ }^{238} \mathrm{U}\right)$ values during mineral-ice contact has not been studied. Notably, the liquid water content of permafrost is a function of mineral surface area and solute content, both of which are expected to be high in yedoma (Tyutyunov, 1956; Romanovsky and Osterkamp, 2000). Thus it is possible that weathering occurs at the pore and particle scale without permafrost thaw. Field observation of redox coloration around ice lenses in frozen core is evidence supportive of these processes (Fig. 2).

\section{RESULTS AND DISCUSSION}

\subsection{Thaw water $\left({ }^{234} \mathrm{U} /{ }^{238} \mathrm{U}\right)$ values}

In the deep cores, the primary variation observed in $\left({ }^{234} \mathrm{U} /{ }^{238} \mathrm{U}\right)$ values of thaw water was the overall increase with depth in all cores except A2 (Table 1, Fig. 6a), in which no near-surface (upper 1-2 m) sample was evaluated due to low ice content. This observation supports the general prediction that thaw-water $\left({ }^{234} \mathrm{U} /{ }^{238} \mathrm{U}\right)$ values should increase with depth in well-preserved syngenetic permafrost developed with loess deposition. Values in near-surface core samples ranged from 1.162 to 1.224 , consistently higher than the most proximal porewater (1.161, Table 2) as compared to porewater near shallow core HC03.4 (Tables 1 and 2). The highest thaw-water $\left({ }^{234} U /{ }^{238} U\right)$ value (1.904) occurred in the lowermost section of the deepest core (A9). Within this overall trend, oscillation of thaw-water $\left({ }^{234} \mathrm{U} /{ }^{238} \mathrm{U}\right)$ with depth was evident in most cores, with the largest oscillation (from 1.904 to 1.541 ) at $\sim 20 \mathrm{~m}$ depth in core A9. As with core A2, samples from A5 showed little variation with depth over the limited interval evaluated $(1.01-6.60 \mathrm{~m})$. These limited variations in $\left({ }^{234} \mathrm{U} /{ }^{238} \mathrm{U}\right)$ are consistent with the hypothesized thaw history of these cores based on ice morphologies (Shur et al., 2010; Kanevskiy et al., 2012), although the more elevated values in core A5 are consistent with the overall depth trend observed in other cores (Fig. 6a).

In upslope cores A2 and A5, the lack of change in thawwater $\left({ }^{234} \mathrm{U} /{ }^{238} \mathrm{U}\right)$ values with depth is consistent with the interpretation of Shur et al. (2010), who suggested that the shallow $(1-4 \mathrm{~m})$ zones of reduced ice content in cores A2 through A5 are the result of past thaw and removal of the thaw water. However, if true, this thaw may have occurred long enough ago to allow for re-development of elevated thaw-water $\left({ }^{234} \mathrm{U} /{ }^{238} \mathrm{U}\right)$ values in core A5 $(1.25$ 1.37, Table 1); alternatively the values in core A5 may reflect homogenization resulting from mixing of higher and lower values. In core A4 the increase with depth is similar to that observed in the deeper cores downslope. This supports the mixing scenario for core A5, which may reflect localized processes associated with cryoturbation, downslope sediment redistribution from the top of core A4, and/or small scale movement of thaw waters due to elevated pore pressures (Wu, 1984; Carey and Woo, 2002; Ping et al., 2008). Overall, however, the increasing thawwater $\left({ }^{234} U /{ }^{238} U\right)$ values with increasing depth in this set of cores is consistent with the concept that that the syngenetic permafrost in place today has behaved predominantly as a closed system and has largely preserved the expected signal of increasing age with depth.

In the shallow cores (Table 1, Fig. 6b), which were sampled at shorter depth intervals of $0.5-3 \mathrm{~m},\left({ }^{234} \mathrm{U} /{ }^{238} \mathrm{U}\right)$ values showed small increases with depth $(1.162-1.273)$ that were consistent with values in the upper sections of the deeper cores (Fig. 6). At depths shallower than $\sim 150 \mathrm{~cm}$, uniform $\left({ }^{234} \mathrm{U} /{ }^{238} \mathrm{U}\right)$ values could indicate removal of thaw water with periodic active layer deepening (current active layer depths are $\sim 50$ to $80 \mathrm{~cm}$; fire-induced deepening of

Table 2

Soil porewater samples, Hess Creek area, 2008-2009.

\begin{tabular}{llllllll}
\hline Date & Tributary & Sample ID & Mass, g & {$[\mathrm{U}](\mathrm{ppb})$} & $\pm 2 \sigma(\mathrm{ppb})$ & $\left({ }^{234} \mathrm{U} / /^{238} \mathrm{U}\right)$ & $\pm 2 \sigma$ \\
\hline Sep-08 & Richardson & HC03.5.TK3 ${ }^{\mathrm{a}}$ & 435.22 & 0.1138 & 0.0004 & 1.184 & 0.009 \\
Sep-09 & Richardson & HC03.5.TK3 & 817.78 & 0.2363 & 0.0008 & 1.199 & 0.005 \\
Sep-08 & Erickson & HC03.1 & 438.70 & 3.9733 & 0.0057 & 1.157 & 0.003 \\
Sep-08 & Erickson & HC03.1.TK1 & 422.83 & 0.0297 & 0.0002 & 1.161 & 0.024 \\
Sep-08 & Erickson & HC03.1.TK2 & 433.04 & 0.1136 & 0.0011 & 1.166 & 0.023 \\
Richardson Creek average $(n=2)$ & & & & & & 1.191 & \\
Erickson Creek average $(n=3)^{2}$ & & & & & & 1.161 &
\end{tabular}

${ }^{\text {a }}$ HC03.TK3 is $\sim 500 \mathrm{~m}$ downslope of core location HC03.5 in Table 1.

b Closest to deep coring location. 

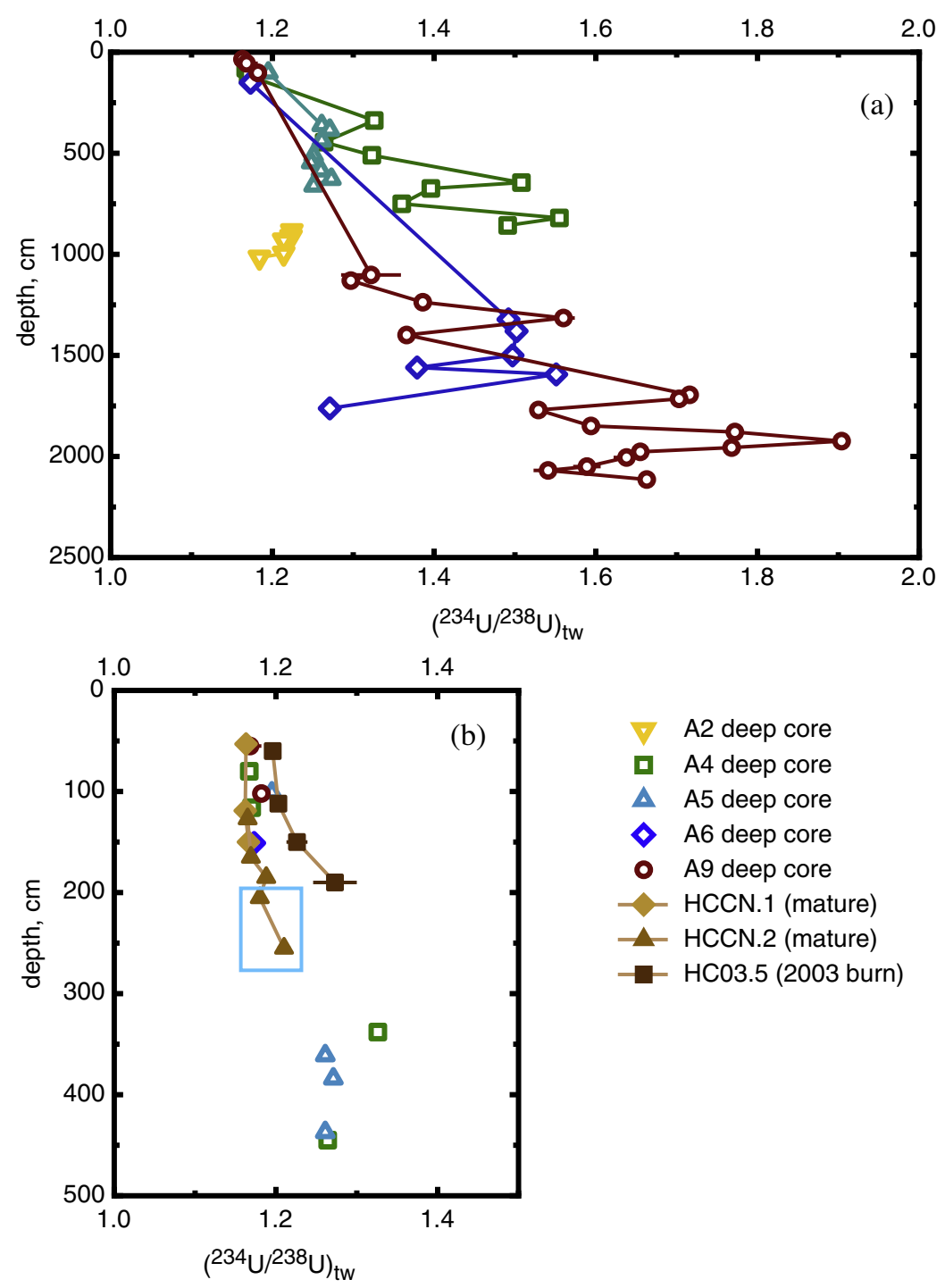

Fig. 6. Measured $\left({ }^{234} \mathrm{U} /{ }^{238} \mathrm{U}\right.$ ) values in thaw waters from (a) five deep cores in the sequence shown in Fig. 2, and (b) nearby shallow cores on burned and unburned sites (O'Donnell et al., 2011a), with deep core values for comparison. Grey box indicates ice wedge samples.

$\sim 20 \mathrm{~cm}$ was observed by O’Donnell et al. (2011a)), and/or mixing of active layer water and sediment with downslope movement or cryoturbation (Carey and Woo, 2002; French and Shur, 2010). O'Donnell et al. (2011a) observed depth trends of ${ }^{14} \mathrm{C}$ in these soils indicating increasing ages of solid-phase organic carbon on the order of $10 \mathrm{ky}$ in the upper $\sim 100 \mathrm{~cm}$. The consistent thaw-water $\left({ }^{234} \mathrm{U} /{ }^{238} \mathrm{U}\right)$ values are equal to or greater than those observed in porewater at these shallowest depths, and imply mixing of active layer water (and perhaps sediment) with seasonal and longer thaw cycles during the Holocene (Jorgenson et al., 2013b).

\subsection{Age model application}

\subsubsection{Leaching experiment: Uranium distribution and isotopic mass balance}

Fractional $\mathrm{U}$ abundances and isotopic compositions (solid vs. fluid) were evaluated using the results of the sequential leach procedure for six samples from core A4 (Table 3, Fig. 7). In all samples, $\left({ }^{234} \mathrm{U} /{ }^{238} \mathrm{U}\right)$ values were greater than 1.0 in thaw water and the first $\mathrm{HCl}$ leach step (Fig. 7a), which yielded considerably more U (12-20\% of the total, Table 3) than was present in thaw waters for these samples (0.03-0.47\%; Table 4; Fig. 7b). These data could indicate that $\mathrm{U}$ is concentrated in readily dissolved secondary precipitates or loosely sorbed onto particle surfaces due to the liquid water component in permafrost (Osmond and Cowart, 2000), which is consistent with observed $U$ series isotope trends in studies of weathering rinds and soils (Pelt et al., 2008; Suresh et al., 2014). Secondary precipitates might include carbonates, which are known to accumulate $U$ and would be released with application of acid. Consistent with this, inorganic carbon concentrations of $\sim 1 \%$ were observed in solid phase analysis (data not shown). To our knowledge, the accumulation of secondary precipitates in ice-rich loess permafrost has not been investigated, and merits further study. 


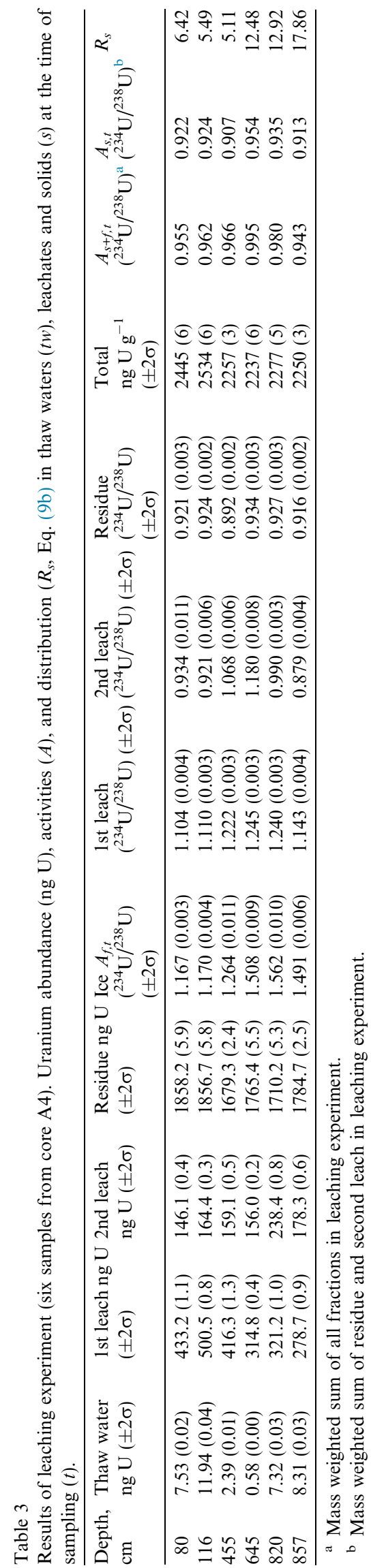

In the second $\mathrm{HCl}$ leach (following ashing), four of six depths yielded $\left({ }^{234} \mathrm{U} /{ }^{238} \mathrm{U}\right)$ values that were less than 1.000 , suggesting that this step was yielding $U$ in the mineral grains subject to recoil depletion. At $857 \mathrm{~cm}$ depth, a minimum $\left({ }^{234} \mathrm{U} /{ }^{238} \mathrm{U}\right)$ value of 0.879 (less than 0.916 observed in the residue) was obtained in the second leach (Table 3).

The mass-weighted summation of $\left({ }^{234} \mathrm{U} /{ }^{238} \mathrm{U}\right)$ values from sequential leaches and residues resulted in $\left({ }^{234} \mathrm{U} /{ }^{238} \mathrm{U}\right)$ values consistently less than 1.000 $\left(A_{s+f, t}=0.943-0.995\right.$; Table 3 and Fig. 7), although uncertainties in the mass balance of core fractions approached $5 \%$. This could indicate that particle transport times reduced the $\left({ }^{234} \mathrm{U} /{ }^{238} \mathrm{U}\right)$ values of loess upon deposition and burial, or that porewaters with $\left({ }^{234} \mathrm{U} /{ }^{238} \mathrm{U}\right)$ values greater than 1.000 were removed by drainage. However, if thaw of higher $\left({ }^{234} \mathrm{U} /{ }^{238} \mathrm{U}\right)$ ice occurred, it likely did not travel far, given limited hydraulic conductivity observed in the loess within this area (Jorgenson et al., 2013b; Koch et al., 2013a,b). This would likely affect the depth distribution of elevated $\left({ }^{234} \mathrm{U} /{ }^{238} \mathrm{U}\right)$ values locally within the core rather than being effectively removed from any depth other than the near surface, where surficial sediment movement might occur.

For each sample in the leach experiment, the initial thaw water values of $\left({ }^{234} \mathrm{U} /{ }^{238} \mathrm{U}\right)$ were interpreted as $A_{f, t}$ because sequential leaches had $\left({ }^{234} \mathrm{U} /{ }^{238} \mathrm{U}\right)$ that consistently fell below these values (Fig. 7, Table 3). We assume that thawing under unbuffered conditions would adequately capture the combined ice and liquid components in permafrost; this assumption should be tested in future with a more targeted leaching procedure developed specifically for permafrost. Ultimately, however, because our procedure sought to capture all $U$ present in each sample, our age estimates are constrained by this mass balance. Residue $\left({ }^{234} \mathrm{U} /{ }^{238} \mathrm{U}\right)$ values were combined with values from the second leach in a weighted average value for $A_{s, t}$ that ranged from 0.907 to 0.954 (Table 3). These values, along with the mass-weighted total $\left({ }^{234} \mathrm{U} /{ }^{238} \mathrm{U}\right)$ values $\left(A_{s+f, t}\right.$; Table 3$)$, were used to calculate the mass fraction of $\mathrm{U}$ in the ice $\left(X_{f}\right)$ and the solidice ratio $\left(R_{S}\right)$ assuming a two-component mixture of solid and fluid/ice (rearranging Eq. (7b) and using the substitution $\left.X_{s}=1-X_{f}\right)$ :

$X_{f}=\frac{A_{s+f, t}-A_{s, t}}{A_{f, t}-A_{s, t}}$

$R_{s}=\frac{X_{s}}{X_{f}}$

The resulting $X_{f}$ values ranged from $5.3 \%$ to $16.4 \%$ $\left(R_{s}=5.1-17.9\right)$ and did not vary systematically with depth (Table 3 ). These results are consistent with previous observations and provided bounds for evaluation of minimum and maximum model ages. The mean $X_{f}$ value of $10.9 \%$ $\left(R_{s}=10.1\right)$ was used to calculate mean model ages for all samples using Eq. (6), and the range $\left(R_{s}=5.1-17.9\right)$ used to calculate maximum and minimum ages (Fig. 8a, Table 4).

In individual samples where $R_{s}$ was evaluated, a fitted $f_{\alpha}$ was determined based on the linear fit of mean model age with depth (Fig. 8a, Table 4). These fitted values (0.064-0.189) were consistent with values observed in 

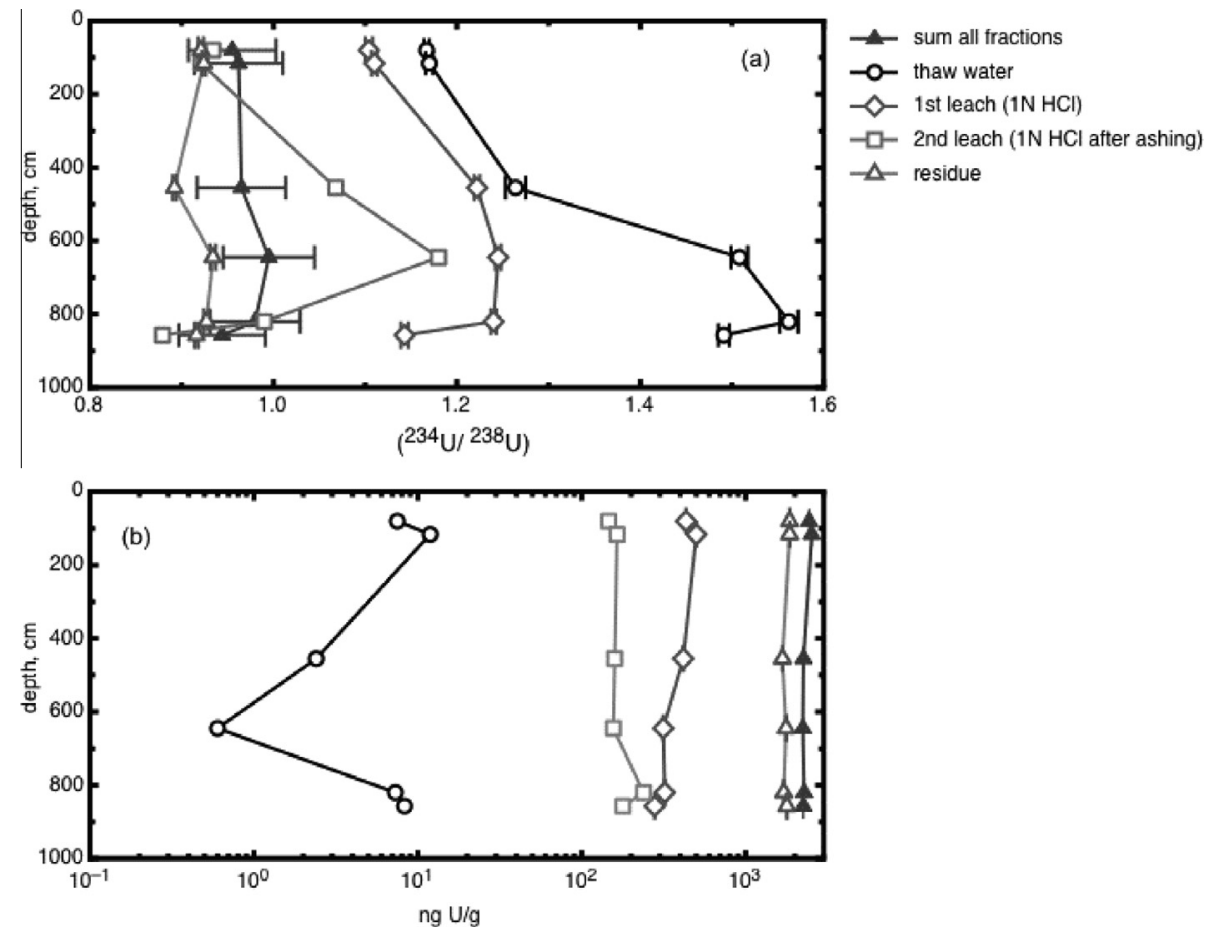

Fig. 7. Leach sequence in six samples from core A4: (a) $\left({ }^{234} \mathrm{U} /{ }^{238} \mathrm{U}\right.$ ) values, and (b) $\mathrm{U}$ concentration distribution (note log scale). Error bars indicate analytical uncertainties shown in Table 3, except in summed fractions $\left({ }^{234} \mathrm{U} /{ }^{238} \mathrm{U}\right)$ where error bars indicate uncertainty of $5 \%$ in the total masses of water/ice and solid.

Table 4

Model ages based on measured $U$ distribution from leaching experiment (core A4).

\begin{tabular}{|c|c|c|c|c|c|c|c|c|}
\hline $\begin{array}{l}\text { Depth, } \\
\mathrm{cm}\end{array}$ & $\begin{array}{l}\text { Thaw water } A_{f, t} \\
\left({ }^{234} \mathrm{U} /{ }^{238} \mathrm{U}\right)^{\mathrm{a}}\end{array}$ & $R_{s}^{\mathrm{b}}$ & $\begin{array}{l}\text { Mean model ice } \\
\text { age, ky eq } 6^{c}\end{array}$ & $\begin{array}{l}\text { Minimum } \\
\text { age, ky }\end{array}$ & $\begin{array}{l}\text { Maximum } \\
\text { age, ky }\end{array}$ & $\begin{array}{l}\text { Model ice age, ky } \\
\text { linear fit }^{\mathrm{e}}\end{array}$ & $\begin{array}{l}\text { Linear fit } \\
f_{\alpha} R_{s}^{\mathrm{f}}\end{array}$ & $\begin{array}{l}\text { Fitted } \\
f_{\alpha}^{\mathrm{g}}\end{array}$ \\
\hline 80 & 1.167 & 6.42 & 1 & 0 & 33 & 5 & 0.417 & 0.065 \\
\hline 116 & 1.170 & 5.49 & 2 & 0 & 36 & 8 & 0.433 & 0.079 \\
\hline 455 & 1.264 & 5.11 & 24 & 6 & 132 & 30 & 1.020 & 0.200 \\
\hline 645 & 1.508 & 12.48 & 89 & 29 & 221 & 43 & 2.261 & 0.181 \\
\hline 820 & 1.562 & 12.92 & 103 & 34 & 502 & 54 & 2.115 & 0.164 \\
\hline 857 & 1.491 & 17.86 & 84 & 27 & 627 & 57 & 1.707 & 0.096 \\
\hline
\end{tabular}

${ }^{\mathrm{a}}$ Uncertainties shown in Table 3.

${ }^{\mathrm{b}}$ Derived using Eq. (9b) and $X_{s}=1-X_{f}$.

${ }^{\mathrm{c}}$ Using mean value of $f_{\alpha} R_{s}=1.715$.

${ }^{\mathrm{d}}$ Minimum and maximum ages derived using Eq. (6) and mean parameter values over the observed range from the leaching experiment and surface area measurements $\left(R_{s}=5.1-17.9, f_{\alpha}=0.111-0.233\right)$.

${ }^{\mathrm{e}}$ Using linear fit for the relationship between mean model age and depth (fitted age $(\mathrm{ky})=0.09888 \times$ depth $(\mathrm{cm}) ;$ Fig. 8).

${ }^{\mathrm{f}}$ Rearranging Eq. (6) to solve for $f_{\alpha} R_{s}$ based on the linear fit of mean model age with depth.

$\mathrm{g}$ Based on linear fit and measured $R_{s}$.

samples where surface area was measured $(0.111-0.233$; Table 5). The assumption of a relatively high $(3-12 \%)$ and constant mass fraction of $\mathrm{U}$ in ice is supported by $\left({ }^{234} \mathrm{U} /{ }^{238} \mathrm{U}\right)$ values at shallow depths in cores (Table 1) that approach those in porewaters (Table 2, Fig. 6b), even as U concentrations remain high at shallow depths in cores (Tables 1 and 2).

Notably the inferred values for $A_{s, t}(0.907$ to 0.954$)$ imply older ages if derived from calculated values for $A_{f+s, i}$ based on Eq. (8b) and using observed $A_{f+s, t}$ and ice ages based on Eq. (6). This could result if (1) $A_{s, i}$ values were initially less than 1.0 , perhaps due to transport or thaw and refreezing; (2) U distributions were not constant through time; and/or (3) porewater values observed today differ from those present at permafrost development. The first possibility is effectively assumed here, such that ages may be underestimates. The second and third possibilities are partially addressed here through calculation of minimum and maximum ages based on observed ranges in values of $A_{s, i}, f_{\alpha}$, and $R_{s}$. The second possibility could be more 

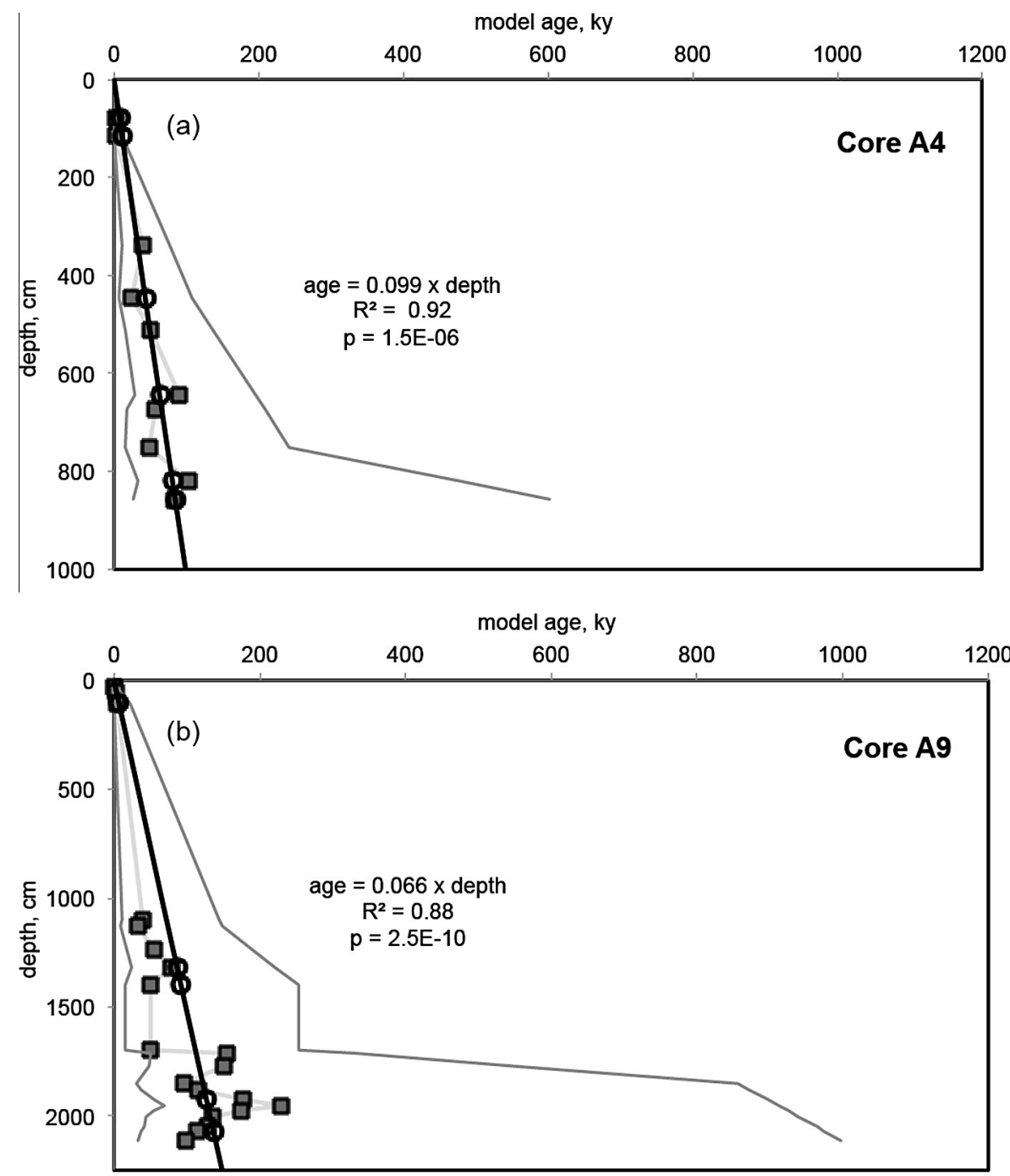

Fig. 8. Model ice ages with depth for all samples from cores A4 (a) and A9 (b). Squares are mean model ice ages using Eq. (6) with mean observed values for recoil fraction based on BET surface area $\left(f_{\alpha}=0.171\right)$ and $\mathrm{U}$ distribution in the mineral solid compared to the ice $\left(R_{s}=10.05\right)$. Solid grey lines indicate maximum model ages based on the minimum $f_{\alpha} R_{s}=0.565$ in Eq. (6) and minimum values based on maximum $f_{\alpha} R_{s}=4.167$ in Eq. (6). Solid black lines indicate linear fits of within-core mean model ages to depth, with $R^{2}$ and $p$ values determined using the $\mathrm{lm}$ function in $R$ (R Core Team, 2012), indicating the age increases with depth are significant and likely different from zero. Circles indicate points where $f_{\alpha}$ (A9, Table 5) or $R_{s}$ (A4, Table 5) was measured. Dark grey lines indicate the upper and lower bounds of age uncertainty, based on variation in model parameters (Table 4, Table 5).

specifically examined through more targeted observations of $U$ distribution with depth in syngenetic permafrost cores. All three could be better evaluated through combination of $\mathrm{U}$-series age assessment with other age constraint in ice-rich loess permafrost.

\subsubsection{Particle size distribution, surface area and recoil loss fractions}

Particle surface area is a primary control on the evolution of $\left({ }^{234} \mathrm{U} /{ }^{238} \mathrm{U}\right)$ in adjacent fluids over time (DePaolo et al., 2006; Maher et al., 2006; Bourdon et al., 2009; Lee et al., 2010; Handley et al., 2013). Bulk surface area in five samples from core A9 (Table 5) reveal smoothing associated with apparent organic coatings (BET surface area increased by a factor of $2-5$ by heating to $350{ }^{\circ} \mathrm{C}$ ). Recoil fractions $\left(f_{\alpha}\right)$ were calculated from the BET surface area of the treated samples using Eq. (1), which consistently exceeded those from the particle size distributions using Eq. (2) (Table 5). Treated BET surface area and PSD derived spherical surface areas $(\beta \lambda=1)$ were positively correlated $\left(R^{2}=0.61, n=5\right)$ with a slope of 28 , a value suggestive of likely aspect ratios (particle dimensions). We note that hydrogen peroxide treatment rather than ashing may be preferred for preservation of mineral surface properties; however the consistency of BET and PSD results is encouraging. Considered individually, BET measurements implied roughness factors of 16-37 compared to smooth spheres, and generally increased with depth, suggesting weathering in cores (Table 5). Lower recoil fractions based on spherical particles or using a fractal model to adjust BET derived 
Table 5

Model ages based on measured surface areas, DOC radiocarbon results, and particle size distributions (Core A9).

\begin{tabular}{|c|c|c|c|c|c|c|c|c|c|c|c|c|}
\hline $\begin{array}{l}\text { Depth, } \\
\mathrm{cm}\end{array}$ & $\begin{array}{l}\text { Thaw } \\
\text { water } A_{f, t} \\
\left({ }^{234} \mathrm{U} /{ }^{238} \mathrm{U}\right)\end{array}$ & $\begin{array}{l}\text { Surface } \\
\text { area, } \\
\mathrm{m}^{2} \mathrm{~g}^{-1} \\
\text { spheres }\end{array}$ & $\begin{array}{l}\text { Surface } \\
\text { area, } \\
\mathrm{m}^{2} \mathrm{~g}^{-1} \\
\text { BET } \\
\text { untreated }\end{array}$ & $\begin{array}{l}\text { Surface } \\
\text { area, } \\
\mathrm{m}^{2} \mathrm{~g}^{-1} \\
\text { BET -OM }\end{array}$ & $\begin{array}{l}\text { Recoil } \\
\text { fraction, } f_{\alpha} \\
\text { Spheres } \\
\beta \lambda=10 \text { eq } 2\end{array}$ & $\begin{array}{l}\text { Recoil } \\
\text { fraction, } f_{\alpha} \\
\text { BET-OM } \\
\text { eq } 1\end{array}$ & $\begin{array}{l}\text { Mean } \\
\text { model ice } \\
\text { age, ky eq } \\
6^{\text {a,b }}\end{array}$ & $\begin{array}{l}\text { Minimum } \\
\text { age, } \mathrm{ky}^{\mathrm{c}}\end{array}$ & $\begin{array}{l}\text { Maximum } \\
\text { age, } \mathrm{ky}^{\mathrm{c}}\end{array}$ & $\begin{array}{l}\text { Model } \\
\text { ice age, } \\
\text { ky linear } \\
\text { fit }^{\mathrm{d}}\end{array}$ & $\begin{array}{l}\text { Linear } \\
\text { fit } \\
f_{\alpha} R_{s}{ }^{\mathrm{e}}\end{array}$ & $\begin{array}{l}\text { Fitted } \\
R_{s}^{\mathrm{f}}\end{array}$ \\
\hline 102 & 1.182 & 0.326 & 1.843 & 9.069 & 0.069 & 0.183 & 7.7 & 0 & 47 & 7 & 1.252 & 6.84 \\
\hline 1315 & 1.560 & 0.248 & 1.294 & 5.487 & 0.054 & 0.111 & 99 & 25 & 169 & 87 & 1.985 & 17.93 \\
\hline 1399 & 1.366 & 0.195 & 3.294 & 7.147 & 0.042 & 0.144 & 105 & 16 & 173 & 93 & 1.048 & 7.27 \\
\hline 1924 & 1.904 & 0.574 & 3.802 & 9.050 & 0.061 & 0.183 & 144 & 56 & 214 & 128 & 2.613 & 14.31 \\
\hline 2069 & 1.541 & 0.551 & 3.887 & 11.566 & 0.059 & 0.233 & 155 & 37 & 245 & 137 & 1.342 & 5.75 \\
\hline
\end{tabular}

${ }^{\text {a }}$ At $102 \mathrm{~cm}$, the ${ }^{14} \mathrm{C}$ age was $8110 \mathrm{y}$. This is the only sample in which both ${ }^{14} \mathrm{C}$-DOC and surface area were evaluated.

${ }^{\mathrm{b}}$ Using mean value of $f_{\alpha} R_{s}=1.715$.

${ }^{c}$ Minimum and maximum ages derived using Eq. (6) and mean parameter values over the observed range from the leaching experiment and surface area measurements $\left(R_{s}=5.1-17.9, f_{\alpha}=0.111-0.233 ; f_{\alpha} R_{s}=0.565-4.1674\right)$.

${ }^{\mathrm{d}}$ Using linear fit for the relationship between mean model age and depth (fitted age $(\mathrm{ky})=0.06628 \times$ depth $(\mathrm{cm})$; Fig. 7).

${ }^{\text {e }}$ Rearranging Eq. (6) to solve for $f_{\alpha} R_{s}$ based on the linear fit of mean model age with depth.

${ }^{\mathrm{f}}$ Based on linear fit and measured $f_{\alpha}$.

recoil fractions $\left(D=2.5\right.$ resulting in $f_{\alpha}=0.022$ to 0.047$)$ (Bourdon et al., 2009; Lee et al., 2010; Handley et al., 2013) were not consistent with calculated solid activity values $\left(A_{s, i} ; A_{s, t}<\left(1-f_{\alpha}\right)\right.$ violating Eq. (5)). Recoil fractions were based on treated BET surface area using Eq. (1) as the more direct measure of that parameter (Table 5). In all samples, the mean observed recoil fraction from BET measurements $\left(f_{\alpha}=0.171\right)$ was used to calculate mean model ages, and the range $(0.111-0.233)$ was used to evaluate maximum and minimum ages (Fig. 8b, Table 5). The observed range of recoil fractions is consistent with previous observations in ice (Fireman, 1986; Goldstein et al.,
2004; Aciego et al., 2011). In individual samples where BET was measured, a fitted $R_{S}$ value was determined based on the linear fit between mean model age and depth (Fig. 8b, Table 5). These values $\left(R_{S}=5.27-16.25\right)$ were consistent with values derived from the leaching experiment (Table $3 ; R_{s}=5.11-17.86$ ).

\subsubsection{Age model applied to all cores}

With the assumption that the distribution of $U$ between the ice and mineral phases has not changed over the lifetime of the permafrost, the age of the ice was then calculated using Eq. (6). To derive model ice ages using Eq. (6), the

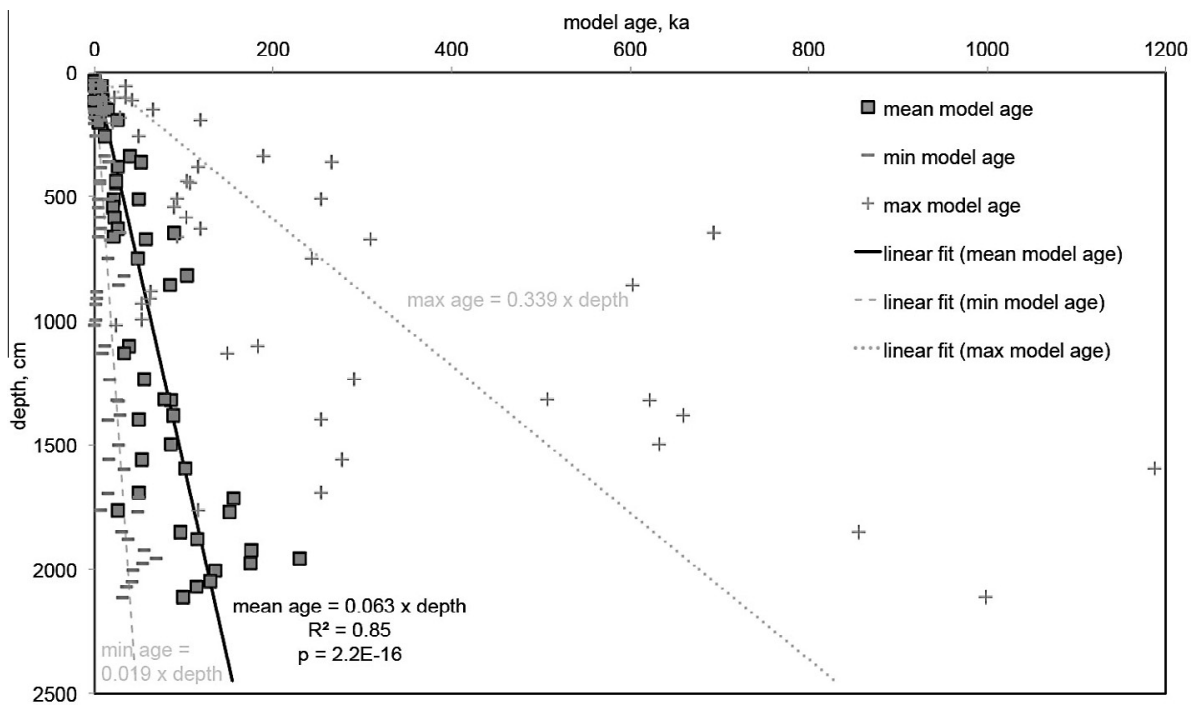

Fig. 9. Model ice ages with depth for all samples from cores A4, A5, A6, A7 and A9 (linear fit improved slightly by omitting A2). Dark symbols are mean model ice ages using Eq. (6) with mean observed values for recoil fraction based on BET surface area $\left(f_{\alpha}=0.171\right)$ and $\mathrm{U}$ distribution in the mineral solid compared to the ice $\left(R_{s}=10.05\right)$. Light symbols indicate maximum model ages based on the minimum $f_{\alpha} R_{s}=0.565$ in Eq. (6) (crosses) and minimum values based on maximum $f_{\alpha} R_{s}=4.167$ in Eq. (6) (bars). Linear fits of model age to depth (R Core Team, 2012) are indicated, with the slope of the mean fit (dark solid line) implying a permafrost accumulation rate of $0.16 \mathrm{~mm} \mathrm{y}^{-1}$. This linear fit is significantly different from zero and is used to assign fitted model ages in Tables 4-6 based on depth. For samples where $f_{\alpha}$ or $R_{s}$ were directly measured, the mean observed $f_{\alpha} R_{s}$ value (1.72) is used to calculate the second parameter in Tables 4 and 5 . Uncertainties of $30-$ $3000 \%$ are implied by the maximum and minimum model ages. 
Table 6

$\left({ }^{234} \mathrm{U} /{ }^{238} \mathrm{U}\right)$, DOC concentrations, and model ages (mean and range) in thaw waters.

\begin{tabular}{|c|c|c|c|c|c|c|c|c|c|}
\hline Sample name ${ }^{\mathrm{a}}$ & $\begin{array}{l}\text { Thaw water } \\
A_{f, t},\left({ }^{234} \mathrm{U} /{ }^{238} \mathrm{U}\right)\end{array}$ & $\pm 2 \sigma$ & $\begin{array}{l}\text { DOC, } \\
\text { ppm }\end{array}$ & $\begin{array}{l}\text { DOC }{ }^{14} \mathrm{C} \\
\text { age, } \mathrm{ky}^{\mathrm{b}}\end{array}$ & $\begin{array}{l}\text { Mean } \\
\text { model } \\
\text { age, } \mathrm{ky}^{\mathrm{c}}\end{array}$ & $\begin{array}{l}\text { Min } \\
\text { age, ky }\end{array}$ & $\begin{array}{l}\text { Max } \\
\text { age, ky }\end{array}$ & $\begin{array}{l}\text { Linear with } \\
\text { depth model } \\
\text { age, } \mathrm{ky}^{\mathrm{f}}\end{array}$ & $\begin{array}{l}f_{\alpha} R_{s} \text { from } \\
\text { linear fit }\end{array}$ \\
\hline HCDT.A2.0885 & 1.224 & 0.007 & & & 15 & 2 & 63 & 56 & 0.588 \\
\hline HCDT.A2.0913 & 1.223 & 0.006 & & & 14 & 2 & 62 & 58 & 0.570 \\
\hline HCDT.A2.0931 & 1.214 & 0.005 & 1081.0 & & 12 & 1 & 53 & 59 & 0.504 \\
\hline HCDT.A2.0996 & 1.214 & 0.006 & 1066.0 & & 12 & 1 & 53 & 63 & 0.483 \\
\hline HCDT.A2.1016 & 1.184 & 0.009 & 1077.0 & & 5 & 0 & 24 & 64 & 0.297 \\
\hline HCDT.A4.0080 & 1.167 & 0.003 & 3.9 & & 1 & 0 & 9 & 5 & 0.559 \\
\hline HCDT.A4.0116 & 1.170 & 0.004 & 3.7 & & 2 & 0 & 11 & 7 & 0.582 \\
\hline HCDT.A4.0338 & 1.326 & 0.007 & & & 40 & 11 & 76 & 21 & 2.961 \\
\hline HCDT.A4.0445 & 1.264 & 0.011 & 1348.0 & & 24 & 6 & 107 & 28 & 1.500 \\
\hline HCDT.A4.0510 & 1.366 & 0.060 & & & 50 & 15 & 136 & 32 & 2.503 \\
\hline HCDT.A4.0645 & 1.508 & 0.009 & 864.0 & & 89 & 29 & 196 & 41 & 3.335 \\
\hline HCDT.A4.0674 & 1.395 & 0.027 & & & 58 & 18 & 209 & 43 & 2.213 \\
\hline HCDT.A4.0750 & 1.360 & 0.007 & & & 48 & 15 & 243 & 48 & 1.740 \\
\hline HCDT.A4.0820 & 1.555 & 0.005 & 1338.0 & & 103 & 33 & 478 & 52 & 3.040 \\
\hline HCDT.A4.0857 & 1.491 & 0.006 & 567.0 & & 84 & 27 & 603 & 54 & 2.475 \\
\hline HCDT.A5.0101 & 1.195 & 0.008 & 75.4 & 9.88 & 8 & 0 & 35 & 6 & 2.037 \\
\hline HCDT.A5.0361 & 1.373 & 0.078 & 585.4 & & 52 & 16 & 67 & 23 & 3.537 \\
\hline HCDT.A5.0384 & 1.271 & 0.004 & 782.2 & & 26 & 6 & 69 & 24 & 1.809 \\
\hline HCDT.A5.0437 & 1.261 & 0.006 & 975.5 & & 23 & 6 & 76 & 28 & 1.483 \\
\hline HCDT.A5.0511 & 1.251 & 0.006 & 1151.6 & & 21 & 5 & 85 & 32 & 1.185 \\
\hline HCDT.A5.0545 & 1.248 & 0.005 & 599.2 & & 20 & 4 & 89 & 35 & 1.092 \\
\hline HCDT.A5.0585 & 1.260 & 0.005 & 398.7 & & 23 & 5 & 90 & 37 & 1.152 \\
\hline HCDT.A5.0627 & 1.273 & 0.007 & 353.7 & $>41.0$ & 26 & 7 & 92 & 40 & 1.211 \\
\hline HCDT.A5.0660 & 1.251 & 0.005 & 392.6 & & 21 & 5 & 92 & 42 & 0.964 \\
\hline HCDT.A6.0151 & 1.173 & 0.005 & & & 3 & 0 & 14 & 10 & 0.598 \\
\hline HCDT.A6.1322 & 1.495 & 0.021 & & & 85 & 27 & 622 & 84 & 1.742 \\
\hline HCDT.A6.1380 & 1.502 & 0.011 & 1499.3 & & 87 & 28 & 659 & 87 & 1.715 \\
\hline HCDT.A6.1500 & 1.497 & 0.011 & 1550.5 & & 86 & 28 & 632 & 95 & 1.584 \\
\hline HCDT.A6.1560 & 1.379 & 0.004 & & & 53 & 16 & 277 & 99 & 1.053 \\
\hline HCDT.A6.1594 & 1.551 & 0.005 & & $>40.3$ & 102 & 33 & 1187 & 101 & 1.728 \\
\hline HCDT.A6.1762 & 1.271 & 0.005 & 869.7 & & 26 & 6 & 116 & 112 & 0.566 \\
\hline HCDT.A9.0035 & 1.163 & 0.012 & 97.9 & & 0 & 0 & 5 & 2 & 0.428 \\
\hline HCDT.A9.0055 & 1.168 & 0.014 & 59.6 & & 2 & 0 & 10 & 3 & 0.840 \\
\hline HCDT.A9.0102 & 1.182 & 0.006 & 49.0 & 8.11 & 5 & 0 & 22 & 6 & 1.301 \\
\hline HCDT.A9.1102 & 1.322 & 0.037 & 775.2 & $>36.4$ & 39 & 11 & 145 & 70 & 1.057 \\
\hline HCDT.A9.1130 & 1.297 & 0.006 & 275.4 & & 32 & 9 & 148 & 72 & 0.901 \\
\hline HCDT.A9.1237 & 1.386 & 0.010 & 544.8 & & 55 & 17 & 190 & 78 & 1.290 \\
\hline HCDT.A9.1315 & 1.468 & 0.014 & 498.7 & & 78 & 25 & 221 & 83 & 1.621 \\
\hline HCDT.A9.1399 & 1.366 & 0.004 & 364.3 & & 50 & 15 & 254 & 89 & 1.084 \\
\hline HCDT.A9.1695 & 1.366 & 0.004 & 711.5 & & 50 & 15 & 254 & 107 & 0.942 \\
\hline HCDT.A9.1715 & 1.716 & 0.006 & 743.5 & & 156 & 49 & 332 & 109 & 2.256 \\
\hline HCDT.A9.1770 & 1.703 & 0.005 & 790.4 & $>39.0$ & 151 & 48 & 547 & 112 & 2.153 \\
\hline HCDT.A9.1849 & 1.529 & 0.007 & 969.7 & & 95 & 31 & 856 & 117 & 1.464 \\
\hline HCDT.A9.1879 & 1.594 & 0.008 & 930.7 & & 115 & 37 & 872 & 119 & 1.674 \\
\hline HCDT.A9.1924 & 1.772 & 0.011 & 682.2 & & 176 & 55 & 896 & 122 & 2.254 \\
\hline HCDT.A9.1956 & 1.904 & 0.014 & 1274.5 & & 230 & 69 & 914 & 124 & 2.671 \\
\hline HCDT.A9.1977 & 1.768 & 0.007 & 618.2 & & 175 & 55 & 925 & 125 & 2.193 \\
\hline HCDT.A9.2005 & 1.655 & 0.011 & 598.3 & & 135 & 43 & 940 & 127 & 1.796 \\
\hline HCDT.A9. 2050 & 1.638 & 0.016 & 709.5 & & 129 & 41 & 964 & 130 & 1.711 \\
\hline HCDT.A9.2069 & 1.589 & 0.017 & 742.8 & & 114 & 37 & 974 & 131 & 1.541 \\
\hline HCDT.A9.2114 & 1.541 & 0.018 & 966.0 & & 99 & 32 & 999 & 134 & 1.364 \\
\hline HCCN.1.053 & 1.163 & 0.006 & & & 0 & 0 & 5 & 3 & 0.337 \\
\hline HCCN.1.119 & 1.162 & 0.003 & & & 0 & 0 & 4 & 8 & 0.193 \\
\hline HCCN.1.150 & 1.166 & 0.004 & & & 1 & 0 & 8 & 10 & 0.337 \\
\hline HCCN.2.127 & 1.165 & 0.003 & & & 1 & 0 & 7 & 8 & 0.324 \\
\hline HCCN.2.165 & 1.169 & 0.003 & & & 2 & 0 & 11 & 10 & 0.424 \\
\hline
\end{tabular}




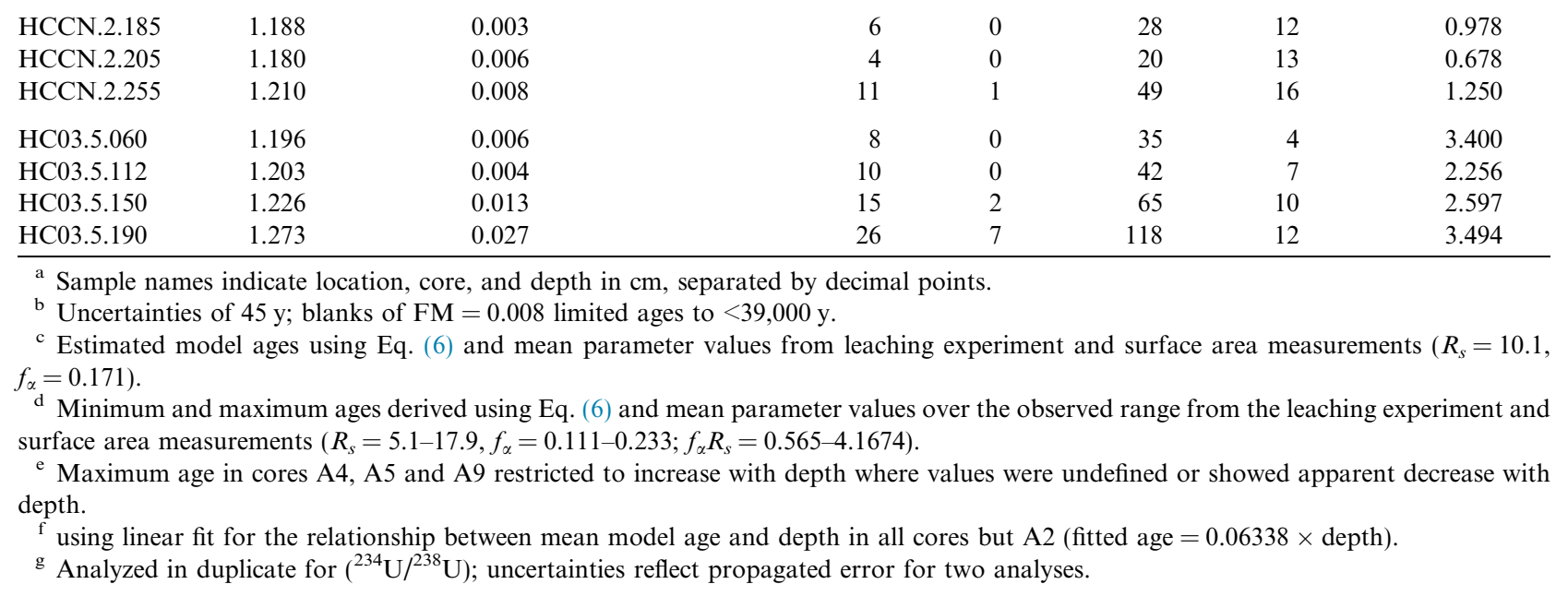

mean recoil loss fraction from the treated BET measurements $\left(f_{\alpha}=0.171\right)$ was combined with the mean mass fraction of $U$ in the mineral compared to the ice based on the leaching experiment $\left(R_{S}=10.1\right)$ and the average porewater $\left({ }^{234} \mathrm{U} /{ }^{238} \mathrm{U}\right)$ value $\left(A_{f, i}=1.161\right)$, resulting in mean model ages ranging from $\sim 1 \mathrm{ky}$ at $\sim 1 \mathrm{~m}$ depth to $\sim 200 \mathrm{ky}$ at $\sim 21 \mathrm{~m}$ depth (Fig. 9, Table 6). Use of the alternate porewater value ( $A_{f, i}=1.191$; Richardson location, Table 2$)$, resulted in undefined ages in the uppermost depths where thaw water values were lower than 1.191 (Table 1), and differences of $\sim 10 \%$ in mean ages at greatest depth. Therefore the value of 1.161 was used, but this is a potentially substantial source of uncertainty that merits further investigation in future permafrost studies.

These mean $\left({ }^{234} \mathrm{U} /{ }^{238} \mathrm{U}\right)$ model ages are consistent with measured ${ }^{14} \mathrm{C}$-DOC ages in cores where radiocarbon data were collected (A5, A6 and A9; Table 6). Radiocarbon ages of $9880 \pm 45{ }^{14} \mathrm{C} \mathrm{y} \mathrm{BP}$ and $8110 \pm 45{ }^{14} \mathrm{C} \mathrm{y} \mathrm{BP}$ were obtained for DOC in thaw water samples at 101-cm depth (A5.0101; Table 6) and 102-cm depth (A9.0102; Table 6), respectively. These ages are consistent with depth sequences of ${ }^{14} \mathrm{C}$ values in adjacent soils and upper permafrost (O'Donnell et al., 2011a). DOC at greater depths (6-18 m) in all three cores (A5, A6, A9) was ${ }^{14} \mathrm{C}$ dead $(>50,000 \mathrm{y} \mathrm{BP})$ within the uncertainty of the blank contribution from sample handling (fraction modern $=\sim 0.008$; Table 6).

The observed range of $f_{\alpha}$ and $R_{s}$ derived from the leaching experiment and surface area measurements $\left(f_{\alpha-}\right.$ $\left.R_{S}=0.57-4.17\right)$ along with the range of observed porewater $\left(A_{f, i}\right)$ values (1.157-1.199; Table 2) were used to derive minimum and maximum ages for all core subsamples (Fig. 9, Table 6). Based on the overall increase in mean model age with depth, a linear fit between depth and the mean model ages in cores A4 through A9 (Fig. 9) was then used to generate a fitted relationship of model age to depth, such that deeper samples were always modeled as older than shallower samples (Fig. 9). The fitted mean model ages were consistent with radiocarbon results (Table 6) and implied values of $f_{\alpha} R_{s}(0.19-3.54)$ that were close to values based on the surface area and leaching experiment results
(0.57-4.17). The model-age uncertainties of $30-3000 \%$ reflect a degree of uncertainty consistent with other studies (Aciego et al., 2011), and speak to the need for combining $\mathrm{U}$ series dating approaches in permafrost with other age constraints or geochronologic tools.

Generally, the observed $\left({ }^{234} \mathrm{U} /{ }^{238} \mathrm{U}\right)$ values indicate minimum model ages up to $\sim 70 \mathrm{ka}$ and mean model ages up to $\sim 200 \mathrm{ka}$ at the base of the core sequence (Table 6, Fig. 9). This encompasses an interval of multiple glacial advances in the Brooks Range (Briner and Kaufman, 2008), and suggests that some regions of the carbon- and ice-rich loess permafrost of interior Alaska have survived more than one full glacial cycle. This is consistent with observations interpreted as long-term persistence of ground ice at the Palisades Bluff near Galena, Alaska (USA) and in the Yukon Territory (Canada) through the last large interglacial (Froese et al., 2008) and highlights the potential resilience of yedoma (ice- and organic-rich loess permafrost) to climate change (Jorgenson et al., 2013b). In addition, recent work on speleothems suggests preservation of permafrost for $>400 \mathrm{ka}$ at similar latitudes in Siberia (Vaks et al., 2013). However, another 30-m-thick ice-rich loess permafrost deposit in northern Alaska dates only about $50 \mathrm{ka}$ based on ${ }^{14} \mathrm{C}$ and thermo-luminescence dating (Kanevskiy et al., 2011). In a separate set of samples from this Hess Creek site, ${ }^{14} \mathrm{C}$ results suggest younger ages ( $\sim 22$ to $43 \mathrm{ka}$ ) (Kanevskiy et al., 2012), although blank signal was uncertain in that analysis. Differences between results from the Kanevskiy et al. study and those presented here illustrate the need for further efforts to combine multiple dating techniques in evaluating the age of yedoma deposits. In particular, the geomorphic context of loess sequences must be considered (Jorgenson et al., 2013b; Koch et al., 2013a). At Hess Creek, a context of hillslope evolution with stream incision has likely resulted in both downslope erosion resulting in exposure of ground ice to thaw; and protection of older ice bodies now overtopped with material from upslope.

The relationship between sample age and depth reflects loess net accumulation rate. Loess deposition rates of $\sim 0.002$ to $\sim 1 \mathrm{~mm} \mathrm{y}^{-1}$ are reported in the region (Muhs 
et al., 2003). Accounting for syngenetic ice content of 50\% by volume of the total core, total accumulation rates of $\sim 0.004$ to $2 \mathrm{~mm} \mathrm{y}^{-1}$ would suggest ages of $10-500 \mathrm{ky}$ in the deepest $(21 \mathrm{~m})$ core here based on these rates. The linear fits in Figs. 8 and 9 suggest accumulation rates of $\sim 0.1 \mathrm{~mm} \mathrm{y}^{-1}$, broadly consistent with regional rates. Therefore, sediment movement by erosion and deposition would appear to be limited at this site, or may have mainly occurred early on following loess deposition.

\subsection{DOC in thaw waters}

DOC concentrations in the deep core thaw waters analyzed in this study increase with depth to maxima $>1000$ ppm (Fig. 10, Table 6), suggesting long-term, in-situ generation of DOC in the unfrozen water fraction of this carbon-rich and presumably oxygen-poor subsurface environment (Romanovsky and Osterkamp, 2000; Weintraub and Schimel, 2003, 2005). Radiocarbon-dead DOC and modeled ice ages of $\sim 3$ to $160 \mathrm{ka}$ imply long-term, slow production of DOC from the included solid phase organic matter. This closed-system production of DOC under anoxic conditions implies that thaw of this permafrost will release a pulse of concentrated, ancient DOC that would likely be highly labile to decomposition upon exposure to oxygen. This DOC character would be consistent with observations of old, labile DOC in meltwater from retreating glaciers in coastal Alaska (Hood et al., 2009), but would contrast with observations of young, labile DOC in arctic rivers and streams during spring runoff (Neff et al., 2006).

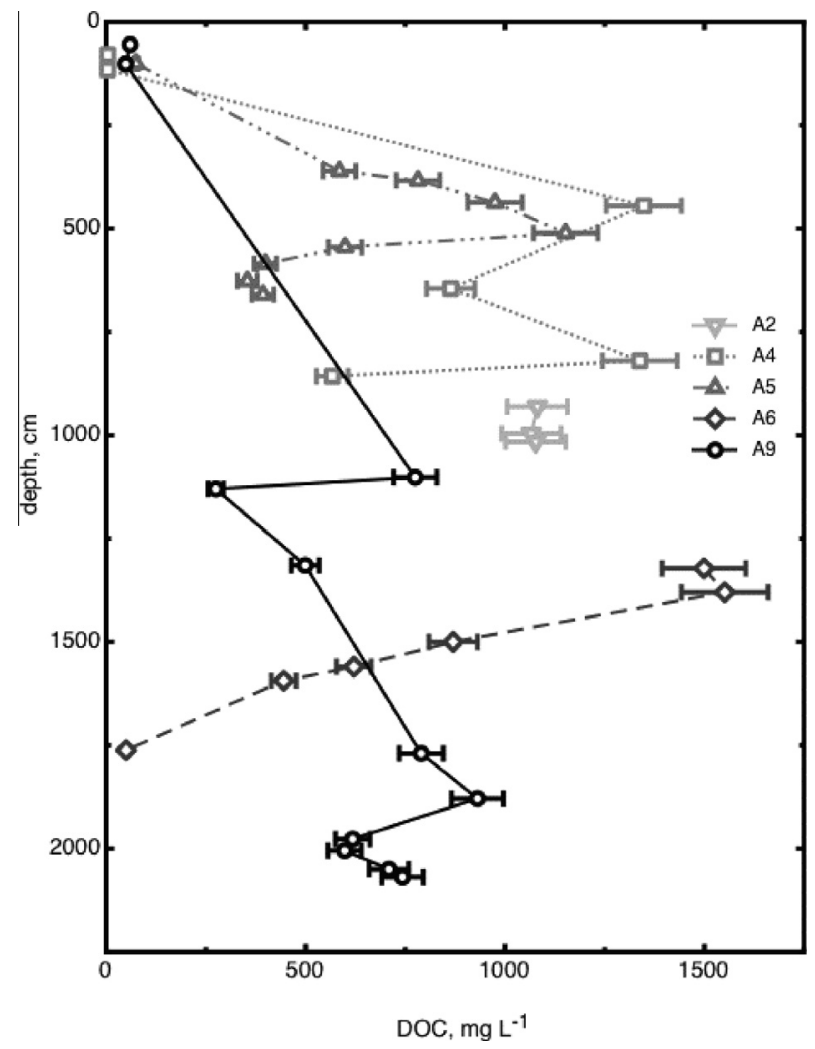

Fig. 10. Dissolved organic carbon (DOC) concentrations with depth in water separated from thawed deep permafrost cores.
This pulsed release of old, labile DOC in permafrost thaw waters could be substantial: DOC in core A9 accounts for $15 \mathrm{~kg} \mathrm{C} \mathrm{m}^{-2}$, or $3.1 \%$ of the total $\mathrm{C}$ inventory of $480 \mathrm{~kg} \mathrm{~m}^{-2}$.

\section{CONCLUSIONS}

This use of $U$ isotopes to directly evaluate the residence time of ice in permafrost demonstrates the potential utility of this technique for understanding past chronologies of climate, and potentially for detecting a signal of thaw in surface waters draining permafrost dominated areas. Although uncertainties in the modeled ages presented here are substantial (30-3000\%), other more suitable sites may permit the combination of this U-series approach with precise indicators of solid phase age, such as tephra deposits, allowing greater refinement of model parameters to yield more precise results (Froese et al., 2008; Jensen et al., 2008, 2011, 2013; Reyes et al., 2010a, b, 2011). In addition, BET surface area should be routinely assessed as argued in other studies, and while the leaching procedure used here provided a reasonable first step, it could be refined. In particular, use of buffered solutions and particle sizing should be considered (Goldstein et al., 2004; Aciego et al., 2011; Suresh et al., 2013, 2014). Nonetheless, this work provides evidence that preservation of ground ice through periods of climate warming is a function of landscape processes such as insulation by downslope sediment redistribution, peat accumulation, and plant community succession, as well as the intrinsic properties of syngenetic loess permafrost (high ice content, low hydraulic conductivity upon thaw, location on water-shedding slopes). Our results support the assertion that thaw of the $\sim 1.5 \mathrm{~m}$ of material overlying ice wedges occurred during the Holocene, as indicated by ${ }^{14} \mathrm{C}$ ages of $<10 \mathrm{ka}$ at depths of $1 \mathrm{~m}$. Whether the shallow thawing developed in response to a warmer climate during the early Holocene or to repeated fire disturbance is uncertain. Nonetheless, our observed $\left({ }^{234} \mathrm{U} /{ }^{238} \mathrm{U}\right)$ values in deep yedoma cores suggest mean model ages up to $\sim 200 \mathrm{ka}$, consistent with other evidence of permafrost preservation for timescales on the order of $\sim 100 \mathrm{ka}$ (Froese et al., 2008; Vaks et al., 2013). Moreover, increasing DOC with depth in cores implies ongoing production of DOC from the surrounding organic matter over these timescales. Upon thaw of loess permafrost, this ancient DOC may be rapidly mineralized, even as the signal of ancient ice as reflected in $\left({ }^{234} \mathrm{U} /{ }^{238} \mathrm{U}\right)$ values should be released into surface water networks.

\section{ACKNOWLEDGEMENTS}

We thank Joshua Koch for ongoing discussion and review of the manuscript. We also thank Leonid Neymark for useful discussion and insight, Kenna Butler for fast and excellent DOC analysis, David Butman and Peter Raymond for DOC- ${ }^{14} \mathrm{C}$ analysis, Paul Schuster and Kathy Kelsey for IC analysis, Tom Oliver for ICP analysis, Merith Reheis and Harland Goldstein for particle size analysis, and Kyungsoo Yoo for surface area analysis. Funding for this work was provided by the USGS climate program, the NSF Carbon-Water program (NSF EAR No. 0630319), and the Montana State University Vice President of Research. We thank 
six anonymous reviewers for detailed and insightful comments on earlier versions of this manuscript. Any use of trade, firm, or product names is for descriptive purposes only and does not imply endorsement by the U.S. Government.

\section{REFERENCES}

Aciego S., Bourdon B., Schwander J., Baur H. and Forieri A. (2011) Toward a radiometric ice clock: uranium ages of the Dome C ice core. Quat. Sci. Rev. 30, 2389-2397.

Aiken G. R. (1992) Chloride interference in the analysis of dissolved organic carbon by the wet oxidation method. Environ. Sci. Technol. 26, 2435-2439.

Andersen M. B., Erel Y. and Bourdon B. (2009) Experimental evidence for U-234-U-238 fractionation during granite weathering with implications for U-234/U-238 in natural waters. Geochim. Cosmochim. Acta 73, 4124-4141.

Barclay D. J., Wiles G. C. and Calkin P. E. (2009) Holocene glacier fluctuations in Alaska. Quat. Sci. Rev. 28, 2034-2048.

Blinov A., Alfimov V., Beer J., Gilichinsky D., Schirrmeister L., Kholodov A., Nikolskiy P., Opel T., Tikhomirov D. and Wetterich S. (2009) Ratio of $\mathrm{Cl}-36 / \mathrm{Cl}$ in ground ice of east Siberia and its application for chronometry. Geochem. Geophys. Geosyst., 10

Bourdon B., Turner S., Henderson G. M. and Lundstrom C. C. (2003) Introduction to U-series geochemistry. Uranium Series Geochem. 52, 1-21.

Bourdon B., Bureau S., Andersen M. B., Pili E. and Hubert A. (2009) Weathering rates from top to bottom in a carbonate environment. Chem. Geol. 258, 275-287.

Briner J. P. and Kaufman D. S. (2008) Late Pleistocene mountain glaciation in Alaska: key chronologies. J. Quat. Sci. 23, 659670.

Carey S. K. and Woo M. K. (2002) Hydrogeomorphic relations among soil pipes, flow pathways, and soil detachments within a permafrost hillslope. Phys. Geogr. 23, 95-114.

Chabaux F., Dequincey O., Lévèque J.-J., Leprun J.-C., Clauer N., Riotte J. and Paquet H. (2003a) Tracing and dating recent chemical transfers in weathering profiles by trace-element geochemistry and ${ }^{238} \mathrm{U}-{ }^{234} \mathrm{U}^{230} \mathrm{Th}$ disequilibria: the example of the Kaya lateritic toposequence (Burkina-Faso). C.R. Geosci. 335, 1219-1231.

Chabaux F., Riotte J. and Dequincey O. (2003b) U-Th-Ra fractionation during weathering and river transport. Uranium Series Geochem. 52, 533-576.

Chabaux F., Ma L., Stille P., Pelt E., Granet M., Lemarchand D., Roupert R. d. C. and Brantley S. L. (2011) Determination of chemical weathering rates from $U$ series nuclides in soils and weathering profiles: principles, applications and limitations. Appl. Geochem. 26(Supplement), S20-S23.

Cheng H., Edwards R. L., Hoff J., Gallup C. D., Richards D. A. and Asmerom Y. (2000) The half-lives of uranium-234 and thorium-230. Chem. Geol. 169, 17-33.

DePaolo D. J., Maher K., Christensen J. N. and McManus J. (2006) Sediment transport time measured with U-series isotopes: results from ODP North Atlantic drift site 984. Earth Planet. Sci. Lett. 248, 394-410.

DePaolo D. J., Lee V. E., Christensen J. N. and Maher K. (2012) Uranium comminution ages: sediment transport and deposition time scales. C.R. Geosci. 344, 678-687.

Dosseto A., Bourdon B., Gaillardet J., Allegre C. J. and Filizola N. (2006a) Time scale and conditions of weathering under tropical climate: study of the Amazon basin with U-series. Geochim. Cosmochim. Acta 70, 71-89.
Dosseto A., Bourdon B., Gaillardet J., Maurice-Bourgoin L. and Allegre C. J. (2006b) Weathering and transport of sediments in the Bolivian Andes: time constraints from uranium-series isotopes. Earth Planet. Sci. Lett. 248, 759-771.

Dosseto A., Bourdon B. and Turner S. P. (2008) Uranium-series isotopes in river materials: insights into the timescales of erosion and sediment transport. Earth Planet. Sci. Lett. 265, 117.

Dosseto A., Hesse P. P., Maher K., Fryirs K. and Turner S. (2010) Climatic and vegetation control on sediment dynamics during the last glacial cycle. Geology 38, 395-398.

Euskirchen E. S., McGuire A. D., Kicklighter D. W., Zhuang Q., Clein J. S., Dargaville R. J., Dye D. G., Kimball J. S., McDonald K. C., Melillo J. M., Romanovsky V. E. and Smith N. V. (2006) Importance of recent shifts in soil thermal dynamics on growing season length, productivity, and carbon sequestration in terrestrial high-latitude ecosystems. Global Change Biol. 12, 731-750.

Fireman E. L. (1986) Uranium series dating of Allan Hills ice. $J$. Geophys. Res. Solid Earth Planet. 91, D539-D544.

Fleischer R. L. (1983) Theory of alpha-recoil effects of radon release and isotopic disequilibrium. Geochim. Cosmochim. Acta 47, 779-784.

French H. and Shur Y. (2010) The principles of cryostratigraphy. Earth Sci. Rev. 101, 190-206.

Froese D. G., Smith D. G. and Clement D. T. (2005) Characterizing large river history with shallow geophysics: middle Yukon River, Yukon Territory and Alaska. Geomorphology 67, 391406.

Froese D. G., Westgate J. A., Reyes A. V., Enkin R. J. and Preece S. J. (2008) Ancient permafrost and a future, warmer arctic. Science 321, 1648-1648.

Gascoyne M. (1992) Paleoclimate determination from cave calcite deposits. Quat. Sci. Rev. 11, 609-632. Available at: http://WOS: A1992JZ34900001.

Goldstein S. J., Murrell M. I., Nishiizumi K. and Nunn A. J. (2004) Uranium-series chronology and cosmogenic Be-10-Cl-36 record of Antarctic ice. Chem. Geol. 204, 125-143.

Grosse G., Harden J., Turetsky M., McGuire A. D., Camill P., Tarnocai C., Frolking S., Schuur E. A. G., Jorgenson T., Marchenko S., Romanovsky V., Wickland K. P., French N., Waldrop M., Bourgeau-Chavez L. and Striegl R. G. (2011) Vulnerability of high-latitude soil organic carbon in North America to disturbance. J. Geophys. Res. Biogeosci., 116

Hamilton T. D. (1982) A late Pleistocene glacial chronology for the southern Brooks Range - stratigraphic record and regional stratigraphy. Geol. Soc. Am. Bull. 93, 700-716.

Hamilton T. D. (2001) Quaternary glacial, lacustrine, and fluvial interactions in the western Noatak basin, Northwest Alaska. Quat. Sci. Rev. 20, 371-391.

Handley H. K., Turner S., Afonso J. C., Dosseto A. and Cohen T. (2013) Sediment residence times constrained by uranium-series isotopes: a critical appraisal of the comminution approach. Geochim. Cosmochim. Acta 103, 245-262.

Harden J. W., O'Neill K. P., Trumbore S. E., Veldhuis H. and Stocks B. J. (1997) Moss and soil contributions to the annual net carbon flux of a maturing boreal forest. J. Geophys. Res. Atmos. 102, 28805-28816.

Harris C., Kern-Luetschg M., Murton J., Font M., Davies M. and Smith F. (2008) Solifluction processes on permafrost and nonpermafrost slopes: Results of a Large-scale Laboratory Simulation. Permafr. Periglac. Process. 19, 359-378. Available at: http://WOS:000261663000003.

Hood E., Fellman J., Spencer R. G. M., Hernes P. J., Edwards R., D'Amore D. and Scott D. (2009) Glaciers as a source of ancient 
and labile organic matter to the marine environment. Nature 462, U1044-U1100.

Hugelius G., Strauss J., Zubrzycki S., Harden J. W., Schuur E. A. G., Ping C.-L., Schirrmeister L., Grosse G., Michaelson G. J., Koven C. D., O’Donnell J. A., Elberling B., Mishra U., Camill P., Yu Z., Palmtag J. and Kuhry P. (2014) Estimated stocks of circumpolar permafrost carbon with quantified uncertainty ranges and identified data gaps. Biogeosciences 11, 6573-6593. Available at: http://www.biogeosciences.net/11/6573/2014/ [Accessed December 4, 2014].

Jaffey A. H., Flynn K. F., Glendeni L, Bentley W. C. and Essling A. M. (1971) Precision measurements of half-lives and specific activities of ${ }^{235} \mathrm{U}$ and ${ }^{238} \mathrm{U}$. Phys. Rev. C 4, 1889-1906.

Jensen B. J. L., Froese D. G., Preece S. J., Westgate J. A. and Stachel T. (2008) An extensive middle to late Pleistocene tephrochronologic record from east-central Alaska. Quat. Sci. Rev. 27, 411-427.

Jensen B. J. L., Preece S. J., Lamothe M., Pearce N. J. G., Froese D. G., Westgate J. A., Schaefer J. and Beget J. (2011) The variegated (VT) tephra: a new regional marker for middle to late marine isotope stage 5 across Yukon and Alaska. Quat. Int. 246, 312-323.

Jensen B. J. L., Reyes A. V., Froese D. G. and Stone D. B. (2013) The Palisades is a key reference site for the middle Pleistocene of eastern Beringia: new evidence from paleomagnetics and regional tephrostratigraphy. Quat. Sci. Rev. 63, 91-108.

Jorgenson M. T., Romanovsky V., Harden J., Shur Y., O’Donnell J., Schuur E. A. G., Kanevskiy M. and Marchenko S. (2010) Resilience and vulnerability of permafrost to climate change. Can. J. For. Res. 40, 1219-1236.

Jorgenson M. T., Harden J., Kanevskiy M., Donnell J. O., Wickland K., Ewing S., Manies K., Zhuang Q., Shur Y., Striegl R. and Koch J. (2013a) Reorganization of vegetation, hydrology and soil carbon after permafrost degradation across heterogeneous boreal landscapes. Environ. Res. Lett. 8, 1-13.

Jorgenson M. T., Harden J., Kanevskiy M., O’Donnell J. A., Wickland K. P., Ewing S. A., Manies K., Zhuang Q., Shur Y., Striegl R. G. and Koch J. (2013b) Reorganization of vegetation, hydrology and soil carbon after permafrost degradation across heterogeneous boreal landscapes. Environ. Res. Lett., 8

Kane E. S., Valentine D. W., Schuur E. A. G. and Dutta K. (2005) Soil carbon stabilization along climate and stand productivity gradients in black spruce forests of interior Alaska. Can. J. For. Res. 35, 2118-2129.

Kanevskiy M., Shur Y., Fortier D., Jorgenson M. T. and Stephani E. (2011) Cryostratigraphy of late Pleistocene syngenetic permafrost (yedoma) in northern Alaska, Itkillik River exposure. Quat. Res. 75, 584-596.

Kanevskiy M., Shur Y., Connor B., Dillon M. R., Stephani E. and O'Donnell J. A. (2012) Study of the ice-rich syngenetic permafrost for road design (Interior Alaska). In Tenth International Conference on Permafrost (ed. K. M. Hinkel). The Northern Publisher, Salekhard, Russia, pp. 191-196.

Kanevskiy M., Jorgenson M. T., Shur Y., O’Donnell J. A., Harden J. W., Zhuang Q. and Fortier D. (2014) Cryostratigraphy and permafrost evolution in lacustrine lowlands of West-Central Alaska. Permafrost Periglac. Process.

Kigoshi K. (1971) Alpha recoil thorium-234 - dissolution into water and uranium-234/uranium-238 disequilibrium in nature. Quat. Int. 173, 47, 47-\&.

Koch J. C., Ewing S. A., Striegl R. and McKnight D. M. (2013a) Rapid runoff via shallow throughflow and deeper preferential flow in a boreal catchment underlain by frozen silt (Alaska, USA). Hydrogeol. J. 21, 93-106.

Koch J. C., Runkel R. L., Striegl R. and McKnight D. M. (2013b) Hydrologic controls on the transport and cycling of carbon and nitrogen in a boreal catchment underlain by continuous permafrost. J. Geophys. Res. Biogeosci. 118, 698-712.

Koven C. D., Ringeval B., Friedlingstein P., Ciais P., Cadule P., Khvorostyanov D., Krinner G. and Tarnocai C. (2011) Permafrost carbon-climate feedbacks accelerate global warming. Proc. Natl. Acad. Sci. USA 108, 14769-14774.

Kraemer T. F. and Brabets T. P. (2012) Uranium isotopes (U-234/ $\mathrm{U}-238$ ) in rivers of the Yukon Basin (Alaska and Canada) as an aid in identifying water sources, with implications for monitoring hydrologic change in arctic regions. Hydrogeol. J. 20, 469-481.

Lachenbruch A. H. and Marshall B. V. (1986) Changing climate geothermal evidence from permafrost in the Alaskan arctic. Science 234, 689-696.

Lawrence D. M., Slater A. G., Tomas R. A., Holland M. M. and Deser C. (2008) Accelerated Arctic land warming and permafrost degradation during rapid sea ice loss. Geophys. Res. Lett., 35

Lee V. E., DePaolo D. J. and Christensen J. N. (2010) Uraniumseries comminution ages of continental sediments: Case study of a Pleistocene alluvial fan. Earth Planet. Sci. Lett. 296, 244 254.

Ludwig K. R., Wallace A. R. and Simmons K. R. (1985) The Schwartzwalder uranium deposit, II: age of uranium mineralization and $\mathrm{Pb}$-isotope constraints on genesis. Econ. Geol. 80, $1858-1871$.

Maher K., DePaolo D. J. and Christensen J. N. (2006) U-Sr isotopic speedometer: fluid flow and chemical weathering rates in aquifers. Geochim. Cosmochim. Acta 70, 4417-4435.

Morgenstern U., Stewart M. K. and Stenger R. (2010) Dating of streamwater using tritium in a post nuclear bomb pulse world: continuous variation of mean transit time with streamflow. Hydrol. Earth Syst. Sci. 14, 2289-2301.

Muhs D. R. and Budahn J. R. (2006) Geochemical evidence for the origin of late Quaternary loess in central Alaska. Can. J. Earth Sci. 43, 323-337.

Muhs D. R., Ager T. A., Bettis E. A., McGeehin J., Been J. M., Beget J. E., Pavich M. J., Stafford T. W. and Stevens D. S. P. (2003) Stratigraphy and palaeoclimatic significance of Late Quaternary loess-palaeosol sequences of the Last InterglacialGlacial cycle in central Alaska. Quat. Sci. Rev. 22, 1947-1986.

Muhs D. R., Bettis, III, E. A., Aleinikoff J. N., McGeehin J. P., Beann J., Skipp G., Marshall B. D., Roberts H. M., Johnson W. C. and Benton R. (2008) Origin and paleoclimatic significance of late Quaternary loess in Nebraska: evidence from stratigraphy, chronology, sedimentology, and geochemistry. Geol. Soc. Am. Bull. 120, 1378-1407.

Neff J. C., Finlay J. C., Zimov S. A., Davydov S. P., Carrasco J. J., Schuur E. A. G. and Davydova A. I. (2006) Seasonal changes in the age and structure of dissolved organic carbon in Siberian rivers and streams. Geophys. Res. Lett., 33

O’Donnell J. A., Harden J. W., McGuire A. D., Kanevskiy M. Z., Jorgenson M. T. and Xu X. (2011a) The effect of fire and permafrost interactions on soil carbon accumulation in an upland black spruce ecosystem of interior Alaska: implications for post-thaw carbon loss. Global Change Biol. 17, 1461-1474.

O'Donnell J. A., Harden J. W., McGuire A. D. and Romanovsky V. E. (2011b) Exploring the sensitivity of soil carbon dynamics to climate change, fire disturbance and permafrost thaw in a black spruce ecosystem. Biogeosciences 8, 1367-1382.

O'Donnell J., Aiken G., Walvoord M., Raymond P., Butler K., Dornblaser M. and Heckman K. (2014) Using dissolved organic matter age and composition to detect permafrost thaw in boreal watersheds of interior Alaska. J. Geophys. Res. Biogeosciences, 2155-2170. Available at: http://onlinelibrary. 
wiley.com/doi/10.1002/2014JG002695/full [Accessed December 30, 2014].

Osmond J. K. and Cowart J. B. (2000) U-series nuclides as tracers in groundwater hydrology. In Environmental Tracers in Catchment Hydrology (eds. P. Cook and A. L. Herczeg). Kluwer Academic Publishers, The Netherlands, pp. 145-173.

Osmond J. K., Cowart J. B. and Ivanovich M. (1983) Uranium isotopic disequilibrium in groundwater as an indicator of anomalies. Int. J. Appl. Radiat. Isot. 34, 283-308.

Osterkamp T. E., Jorgenson M. T., Schuur E. A. G., Shur Y. L., Kanevskiy M. Z., Vogel J. G. and Tumskoy V. E. (2009) Physical and ecological changes associated with warming permafrost and thermokarst in interior Alaska. Permafrost Periglac. Process. 20, 235-256.

Paces J. B., Ludwig K. R., Peterman Z. E. and Neymark L. A. (2002) U-234/U-238 evidence for local recharge and patterns of ground-water flow in the vicinity of Yucca Mountain, Nevada, USA. Appl. Geochem. 17, 751-779.

Pelt E., Chabaux F., Innocent C., Navarre-Sitchler A. K., Sak P. B. and Brantley S. L. (2008) Uranium-thorium chronometry of weathering rinds: rock alteration rate and paleo-isotopic record of weathering fluids. Earth Planet. Sci. Lett. 276, 98-105.

Pelt E., Chabaux F., Stille P., Innocent C., Ghaleb B., Gérard M. and Guntzer F. (2013) Atmospheric dust contribution to the budget of U-series nuclides in soils from the Mount Cameroon volcano. Chem. Geol. 341, 147-157.

Pewe T. L. (1975) Quaternary geology of Alaska. In: USGS Professional Paper (ed. Survey, U.S.G.). Washington, DC. p. 145.

Ping C.-L., Michaelson G. J., Jorgenson M. T., Kimble J. M., Epstein H., Romanovsky V. E. and Walker D. A. (2008) High stocks of soil organic carbon in the North American Arctic region. Nat. Geosci. 1, 615-619.

Pogge von Strandmann P. A. E., Burton K. W., Porcelli D., James R. H., van Calsteren P. and Gislason S. R. (2011) Transport and exchange of $\mathrm{U}$-series nuclides between suspended material, dissolved load and colloids in rivers draining basaltic terrains. Earth Planet. Sci. Lett. 301, 125-136.

Porcelli D. and Swarzenski P. W. (2003) The behavior of U- and Th-series nuclides in groundwater. Uranium Series Geochem. 52, 317-361.

R Core Team (2012). R: A language and environment for statistical computing. R Foundation for Stastical Computing, Vienna, Austrailia.

Raymond P. A. and Bauer J. E. (2001) DOC cycling in a temperate estuary: a mass balance approach using natural C-14 and C-13 isotopes. Limnol. Oceanogr. 46, 655-667.

Raymond P. A., Bauer J. E., Caraco N. F., Cole J. J., Longworth B. and Petsch S. T. (2004) Controls on the variability of organic matter and dissolved inorganic carbon ages in northeast US rivers. Mar. Chem. 92, 353-366.

Reimer P. J., Baillie M. G. L., Bard E., Bayliss A., Beck J. W., Blackwell P. G., Ramsey C. B., Buck C. E., Burr G. S., Edwards R. L., Friedrich M., Grootes P. M., Guilderson T. P., Hajdas I., Heaton T. J., Hogg A. G., Hughen K. A., Kaiser K. F., Kromer B., McCormac F. G., Manning S. W., Reimer R. W., Richards D. A., Southon J. R., Talamo S., Turney C. S. M., van der Plicht J. and Weyhenmeye C. E. (2009) INTCAL09 and MARINE09 radiocarbon age calibration curves, 050,000 years cal bp. Radiocarbon 51, 1111-1150.

Reyes A. V., Froese D. G. and Jensen B. J. L. (2010a) Permafrost response to last interglacial warming field evidence from nonglaciated Yukon and Alaska. Quat. Sci. Rev. 29, 3256-3274.

Reyes A. V., Jensen B. J. L., Zazula G. D., Ager T. A., Kuzmina S., La Farge C. and Froese D. G. (2010b) A late-Middle Pleistocene (Marine Isotope Stage 6) vegetated surface buried by Old Crow tephra at the Palisades, interior Alaska. Quat. Sci. Rev. 29, 801-811.

Reyes A. V., Zazula G. D., Kuzmina S., Ager T. A. and Froese D. G. (2011) Identification of last interglacial deposits in eastern Beringia: a cautionary note from the Palisades, interior Alaska. J. Quat. Sci. 26, 345-352.

Robinson L. F., Henderson G. M., Hall L. and Matthews I. (2004) Climatic control of riverine and Seawater uranium-isotope ratios. Science 305, 851-854.

Romanovsky V. E. and Osterkamp T. E. (2000) Effects of unfrozen water on heat and mass transport processes in the active layer and permafrost. Permafrost Periglac. Process. 11, 219-239.

Romanovsky V. E., Smith S. L. and Christiansen H. H. (2010) Permafrost thermal state in the polar northern hemisphere during the international polar year 2007-2009: a synthesis. Permafrost Periglac. Process. 21, 106-116.

Schirrmeister L., Siegert C., Kuznetsova T., Kuzmina S., Andreev A., Kienast F., Meyer H. and Bobrov A. (2002) Paleoenvironmental and paleoclimatic records from permafrost deposits in the Arctic region of Northern Siberia. Quat. Int. 89, 97-118.

Schuur E. A. G., Bockheim J., Canadell J. G., Euskirchen E., Field C. B., Goryachkin S. V., Hagemann S., Kuhry P., Lafleur P. M., Lee H., Mazhitova G., Nelson F. E., Rinke A., Romanovsky V. E., Shiklomanov N., Tarnocai C., Venevsky S., Vogel J. G. and Zimov S. A. (2008) Vulnerability of permafrost carbon to climate change: implications for the global carbon cycle. Bioscience 58, 701-714.

Shur Y. L. and Jorgenson M. T. (2007) Patterns of permafrost formation and degradation in relation to climate and ecosystems. Permafrost Periglac. Process. 18, 7-19.

Shur Y., Kanevskiy M., White D. M. and Connor B. (2010) Geotechnical investigations for the Dalton Highway innovation project as a case study of the ice-rich syngenetic permafrost.

Smalley I. J., Kumar R., Dhand K. O., Jefferson I. F. and Evans R. D. (2005) The formation of silt material for terrestrial sediments: particularly loess and dust. Sed. Geol. 179, 321-328.

Steiger R. H. and Jager E. (1977) Subcommission on geochronology: convention on the use of decay constants in geo- and cosmochronology. Earth Planet. Sci. Lett. 36, 359-362.

Suresh P. O., Dosseto a., Hesse P. P. and Handley H. K. (2013) Soil formation rates determined from Uranium-series isotope disequilibria in soil profiles from the southeastern Australian highlands. Earth Planet. Sci. Lett. 379, 26-37.

Suresh P. O., Dosseto A., Handley H. K. and Hesse P. P. (2014) Assessment of a sequential phase extraction procedure for uranium-series isotope analysis of soils and sediments. Appl. Radiat. Isot. 83(Pt A), 47-55.

Swanson D. K. (1996) Susceptibility of permafrost soils to deep thaw after forest fires in interior Alaska, USA, and some ecologic implications. Arct. Alp. Res. 28, 217-227.

Tarnocai C., Canadell J. G., Schuur E. A. G., Kuhry P., Mazhitova G. and Zimov S. (2009) Soil organic carbon pools in the northern circumpolar permafrost region. Global Biogeochem. Cycles, 23.

Tyutyunov I. A. (1956) Physical and chemical processes in frozen soils. In Fundamentals of Geocryology (Permafrost Science) Part 1 General Geocryology (eds. P. F. Shvetsov and B. A. Dostovalov). USSR Academy of Sciences, Moscow, pp. 115121.

Vaks A., Gutareva O. S., Breitenbach S. F. M., Avirmed E., Mason A. J., Thomas A. L., Osinzev A. V., Kononov A. M. and Henderson G. M. (2013) Speleothems reveal 500,000-year history of Siberian permafrost. Science 340, 183-186. Available at: http://www.ncbi.nlm.nih.gov/pubmed/23429705 [Accessed December 17, 2014]. 
Viereck L. A., Dyrness C. T., Batten A. R. and Wenzlick K.J. (1992) The Alaska vegetation classification.

Vigier N., Bourdon B., Turner S. and Allegre C. J. (2001) Erosion timescales derived from U-decay series measurements in rivers. Earth Planet. Sci. Lett. 193, 549-563.

Vigier N., Burton K. W., Gislason S. R., Rogers N. W., Duchene S., Thomas L., Hodge E. and Schaefer B. (2006) The relationship between riverine $\mathrm{U}$-series disequilibria and erosion rates in a basaltic terrain. Earth Planet. Sci. Lett. 249, 258-273.

Wagai R., Mayer L. M. and Kitayama K. (2009) Extent and nature of organic coverage of soil mineral surfaces assessed by a gas sorption approach. Geoderma 149, 152-160.

Weintraub M. N. and Schimel J. P. (2003) Interactions between carbon and nitrogen mineralization and soil organic matter chemistry in arctic tundra soils. Ecosystems 6, 129-143.

Weintraub M. N. and Schimel J. P. (2005) The seasonal dynamics of amino acids and other nutrients in Alaskan Arctic tundra soils. Biogeochemistry 73, 359-380.
Wright J. S. (1995) Glacial comminution of quartz sand grains and the production of loessic silt: a simulation study. Quat. Sci. Rev. 14, 669-680.

Wright J. (2001) Making loess-sized quartz silt: data from laboratory simulations and implications for sediment transport pathways and the formation of 'desert' loess deposits associated with the Sahara. Quat. Int. 76-7, 7-19.

Wu T. H. (1984) Soil movements on permafrost slopes near Fairbanks, Alaska. Can. Geotech. J. 21, 699-709.

Zimov S. A., Schuur E. A. G. and Chapin F. S. (2006) Permafrost and the global carbon budget. Science 312, 1612-1613.

Zimov N. S., Zimov S. A., Zimova A. E., Zimova G. M., Chuprynin V. I. and Chapin, III, F. S. (2009) Carbon storage in permafrost and soils of the mammoth tundra-steppe biome: role in the global carbon budget. Geophys. Res. Lett., 36

Associate editor: Miryam Bar-Matthews 